\title{
Increased levels of short-chain ceramides modify the lipid organization and reduce the lipid barrier of skin model membranes
}

Uche, L.E.; Gooris, G.S.; Bouwstra, J.A.; Beddoes, C.M.

\section{Citation}

Uche, L. E., Gooris, G. S., Bouwstra, J. A., \& Beddoes, C. M. (2021). Increased levels of shortchain ceramides modify the lipid organization and reduce the lipid barrier of skin model membranes. Langmuir, 37(31), 9478-9489. doi:10.1021/acs.langmuir.1c01295

Version: $\quad$ Publisher's Version

License: $\quad$ Creative Commons CC BY-NC-ND 4.0 license

Downloaded from: https://hdl.handle.net/1887/3214550

Note: To cite this publication please use the final published version (if applicable). 


\title{
Increased Levels of Short-Chain Ceramides Modify the Lipid Organization and Reduce the Lipid Barrier of Skin Model Membranes
}

\author{
Lorretta E. Uche, Gerrit S. Gooris, Joke A. Bouwstra,* and Charlotte M. Beddoes
}

Cite This: Langmuir 2021, 37, 9478-9489

Read Online

ABSTRACT: The skin barrier function is attributed to the stratum corneum (SC) intercellular lipid matrix, which is composed primarily of ceramides (CERs), free fatty acids, and cholesterol. These lipids are organized in two lamellar phases: the short and long periodicity phases (SPP and LPP), respectively. The LPP is considered important for the skin barrier function. High levels of short-chain CERs are observed in various inflammatory skin diseases and have been correlated with barrier dysfunction. In this research, we investigated how the increase in the fraction of the short-chain CER with a nonhydroxy C16 acyl chain linked to a C18 sphingosine base CER NS(C16) at the expense of the physiological chain length CER NS with a C24 acyl chain (CER NS(C24)) impacts the microstructure and barrier function of a
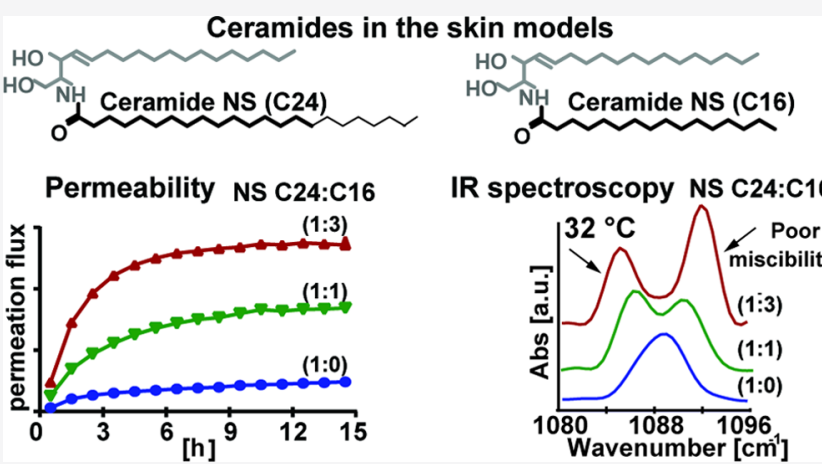

IR spectroscopy NS C24:C16

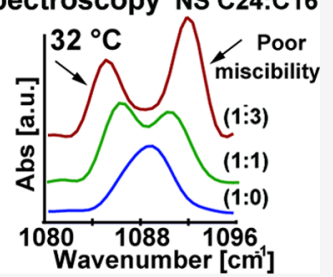
lipid model that mimicked certain characteristics of the SC lipid organization. The permeability and lipid organization of the model membranes were compared with that of a control model without CER NS(C16). The permeability increased significantly when $\geq 50 \%$ of CER NS(C24) was substituted with CER NS(C16). Employing biophysical techniques, we showed that the lipid packing density reduced with an increasing proportion of CER NS(C16). Substitution of 75\% of CER NS(C24) by CER NS(C16) resulted in the formation of phase-separated lipid domains and alteration of the LPP structure. Using deuterium-labeled lipids enabled simultaneous characterization of the $\mathrm{C} 24$ and $\mathrm{C} 16$ acyl chains in the lipid models, providing insight into the mechanisms underlying the reduced skin barrier function in diseased skin.

\section{INTRODUCTION}

Ceramides (CERs) are one of the main lipid classes present in the intercellular regions of the stratum corneum (SC), which is the outermost layer of the skin. They belong to the lipid class referred to as sphingolipids, which are important components of biological membranes and are involved in several biological processes including apoptosis, inflammation, cell proliferation, and differentiation. ${ }^{1-5}$ Together with cholesterol (CHOL) and free fatty acids (FFAs), CERs form a crystalline lipid matrix in the $S^{6-10}$ that creates a barrier against the permeation of pathogenic organisms and other hazardous materials into the body and preventing excessive water loss from inside the body. ${ }^{8,11-16}$ In healthy skin, the SC lipids are organized in two lamellar phases with a repeat distance of approximately 6 and $13 \mathrm{~nm}$ referred to as the short and long periodicity phases (SPP and LPP), respectively. ${ }^{17-19}$

The structure of the CERs in SC is unusual as it contains a long-chain fatty acid (FA) linked by an amide bond to a sphingoid base with a chain length of predominantly 18 carbon atoms. $^{20,21}$ Diversity in the CER headgroup manifests as variations in the type and degree of hydroxylation and saturation. CERs also vary in the acyl chain length and to a lesser extent in the sphingoid base chain length. These variations result in the heterogeneity of the CERs and hence the numerous CER subclasses in the skin barrier. ${ }^{21-29}$ Healthy human skin contains predominantly long acyl chain length CERs of $>22$ carbon chain length. ${ }^{30}$

Alterations of the CER subclass composition and CER chain length have been reported in SC of patients of several inflammatory skin diseases including atopic dermatitis $(\mathrm{AD})$, lamellar ichthyosis, Netherton syndrome, psoriasis, and autosomal-recessive congenital ichthyosis. ${ }^{31-42}$ With regard to chain length variation, a reduction in long-chain CER levels was reported in diseased skin. CERs with a total chain length of 34 carbon atoms increased significantly in Netherton syndrome and $\mathrm{AD}$ patients when compared with healthy individuals. $^{31,34,37,43}$ Since several alterations in the lipid

Received: May 18, 2021

Revised: July 9, 2021

Published: July 28, 2021 
composition occur simultaneously in these patients, the isolated single effect of the shortened CER chain length on SC lipid organization and barrier function cannot be determined in clinical studies. To combat such challenges, model lipid membranes based on synthetic lipids were developed and employed to study the relationship between specific lipid compositional changes, lipid organization, and barrier function. ${ }^{44-47}$ This is attractive because the composition of the lipid model prepared with synthetic lipids is well defined and can be altered on demand to simulate the desired conditions. To acquire more detailed information on the lipid arrangement, we minimized the number of lipids. The CER subclasses used in this study are CER EOS and CER NS. In previous studies, it was reported that the use of these CER subclasses resulted in a lipid phase behavior mimicking important aspects of the lipid organization in SC, such as the formation of the LPP with a primarily orthorhombic packing. ${ }^{48-52}$ The molecular structures and acronyms used to denote the lipids are provided in Figure S1.

Previous investigations reported that model membranes prepared with short-chain CERs exhibited higher permeability compared with their counterparts containing the physiological acyl chain length CER NS(C24) ${ }^{53,54}$ and thus mimic similar consequences that are seen with diseased skin. The lower permeability of the SC models containing CER NS(C24) compared with that of the counterparts containing short-chain CERs was attributed to the higher packing density of the former, as determined by Fourier transform infrared spectroscopy (FTIR). ${ }^{53}$ In another study that employed ${ }^{2} \mathrm{H}$ NMR spectroscopy, CER NS(C24) containing model also exhibited a more dense orthorhombic packing, while the short-chain CER counterpart was mostly in the less dense hexagonal phase at the skin temperature. ${ }^{55}$ The models employed in the abovementioned studies contained entirely long or short acyl chain CER NS, while the diseased skin contains varying proportions of CERs with shorter acyl chains and CERs with a longer acyl chain. ${ }^{43}$ Thus, the studies did not consider differences in the proportions of the short-chain CERs, which may contribute to the severity of barrier dysfunction. Furthermore, the lipid model mixtures used in the previous studies did not contain the acylCERs such as $\mathrm{N}$-(30-linoleoyloxy-triacontanoyl)sphingosine (CER EOS(C30)). These acylCERs are essential for the formation of the LPP, which is a unique trilayer lamellar structure only present in the SC and considered important for the barrier function of the skin. ${ }^{56-60}$ Within the lamellae, the lipids form predominantly the dense orthorhombic packing contributing to the permeability barrier of the SC. ${ }^{61,62}$ Understanding the interactions of lipids within this unique lamellar phase is therefore essential to unravel the mechanisms and processes underlying the barrier function in both healthy and diseased skin.

In this research, we aimed to systematically investigate how the inclusion of various proportions of CER with a nonhydroxy C16 acyl chain linked to a $\mathrm{C} 18$ sphingosine base (total chain length of 34 carbon atoms) referred to as CER NS(C16) will impact the microstructure and barrier function within the SC lipid model. We hypothesize that the extent of the change in lipid composition and organization contributes to the severity of barrier dysfunction. For our study, we prepared SC models gradually increasing in concentration of CER NS(C16) at the expense of CER NS with an acyl chain of 24 carbon atoms (NS (C24)) and a total chain length of 42 carbon atoms. Besides CER NS, CER EOS was also present together with CHOL and
FA(C24), one of the most prevalent FFAs in the SC. ${ }^{63}$ The effect of the short-chain CER NS on the barrier function was evaluated by permeation studies, while the lipid phase behavior was examined by small-angle X-ray diffraction (SAXD) and FTIR. Deuterium-labeled lipids were used to provide more detailed information on the interactions between the various molecules, including phase separation.

\section{EXPERIMENTAL SECTION}

Materials. $\mathrm{N}$-(30-Linoleoyloxy-triacontanoyl)-sphingosine (CER EOS C30), N-(tetracosanoyl)-sphingosine (CER NS (C24)), and CER NS(C24) with a deuterated fatty acid moiety (D-CER NS(C24)) were gifted by Evonik (Essen, Germany). N-(Palmitoyl)sphingosine (CERs NS(C16)) and CER NS(C16) with a deuterated fatty acid moiety (D-CER NS(C16)) were purchased from Avanti. Lignoceric acid (FA (C24)), CHOL, ethyl-p-aminobenzoate (EPABA), and acetate buffer salts were obtained from Sigma-Aldrich Chemie GmbH (Schnelldorf, Germany). FA(C24) with the acyl chain deuterated (DFA(C24)) was purchased from Arc Laboratories B.V. (Apeldoorn, The Netherlands). Nucleopore polycarbonate filter disks (pore size $0.05 \mu \mathrm{m}$ ) were ordered from Whatman (Kent, U.K.). All organic solvents were of analytical or high-performance liquid chromatography grade. Ultrapure water was obtained through a Milli-Q integral water purification system with a resistivity of $18 \mathrm{M} \Omega$ $\mathrm{cm}$ at $25^{\circ} \mathrm{C}$ (Millipore, Bedford, MA).

Composition of the Model Lipid Mixtures. SC lipid models were prepared from CERs, CHOL, and $\mathrm{FA}(\mathrm{C} 24)$ in an equimolar ratio. The CER composition in the control model consisted of CER EOS (40 mol \% of the total CER fraction) and $60 \mathrm{~mol} \%$ CER NS(C24). The composition with CER EOS at $40 \mathrm{~mol} \%$ was selected to ensure that only the LPP was formed. ${ }^{4-51,64,65}$ The model was denoted as NS(C16)-0 indicating the absence of CER NS (C16). Other models were prepared in which 25,50 , and $75 \%$ of the total amount of CER NS(C24) were replaced with CER NS(C16), referred to as NS(C16)-25, NS(C16)-50, and NS(C16)-75, respectively (see Table 1). Analogous models were prepared but with FA(C24) substituted with the deuterated counterpart denoted by -DFA as a

Table 1. Composition of All of the Models Used in the Study

\begin{tabular}{|c|c|}
\hline $\begin{array}{l}\text { lipid model } \\
\text { name }\end{array}$ & $\begin{array}{l}\text { CER composition in a } \mathrm{CER} / \mathrm{CHOL} / \mathrm{FA} \text { (C24) equimolar } \\
\text { ratio }(1: 1: 1)\end{array}$ \\
\hline $\begin{array}{l}\text { NS(C16)-0 } \\
\text { (control) }\end{array}$ & $\begin{array}{l}\text { [CER EOS(C30) } 0.4+\text { CER NS(C24) } 0.6] / \mathrm{CHOL} / \\
\text { FA(C24) }\end{array}$ \\
\hline NS(C16)-25 & $\begin{array}{l}\text { [CER EOS(C30) } 0.4+\text { CER NS(C24) } 0.45+\text { CER } \\
\text { NS(C16) } 0.15] / \text { CHOL/FA(C24) }\end{array}$ \\
\hline $\mathrm{NS}(\mathrm{C} 16)-50$ & $\begin{array}{l}\text { [CER EOS(C30) } 0.4+\text { CER NS(C24) } 0.3+\text { CER } \\
\text { NS(C16) } 0.3 \text { / CHOL/FA(C24) }\end{array}$ \\
\hline $\mathrm{NS}(\mathrm{C} 16)-75$ & $\begin{array}{l}\text { [CER EOS(C30) } 0.4+\text { CER NS(C24) } 0.15+\text { CER } \\
\text { NS(C16) } 0.45] / \text { CHOL/FA(C24) }\end{array}$ \\
\hline $\begin{array}{l}\text { NS(C16)-0- } \\
\text { DFA }\end{array}$ & $\begin{array}{l}\text { [CER EOS(C30) } 0.4+\text { CER NS(C24) } 0.6] / \mathrm{CHOL} / \\
\text { DFA(C24) }\end{array}$ \\
\hline $\begin{array}{l}\text { NS(C16)-25- } \\
\text { DFA }\end{array}$ & $\begin{array}{l}\text { [CER EOS(C30) } 0.4+\text { CER NS(C24) } 0.45+\text { CER } \\
\text { NS(C16) } 0.15] / \text { CHOL/DFA(C24) }\end{array}$ \\
\hline $\begin{array}{l}\text { NS(C16)-50- } \\
\text { DFA }\end{array}$ & $\begin{array}{l}\text { [CER EOS(C30) } 0.4+\text { CER NS(C24) } 0.3+\text { CER } \\
\text { NS(C16) 0.3]/CHOL/DFA(C24) }\end{array}$ \\
\hline $\begin{array}{l}\text { NS(C16)-75- } \\
\text { DFA }\end{array}$ & $\begin{array}{l}\text { [CER EOS(C30) } 0.4+\text { CER NS(C24) } 0.15+\text { CER } \\
\text { NS(C16) } 0.45] / \text { CHOL/DFA(C24) }\end{array}$ \\
\hline $\begin{array}{l}\text { D24-NS(C16)- } \\
50\end{array}$ & $\begin{array}{l}\text { [CER EOS(C30) } 0.4+\text { D-CER NS(C24) } 0.3+\text { CER } \\
\text { NS(C16) } 0.3 \text { / CHOL/FA(C24) }\end{array}$ \\
\hline $\begin{array}{l}\text { D16-NS(C16)- } \\
50\end{array}$ & $\begin{array}{l}\text { [CER EOS(C30) } 0.4+\text { CER NS(C24) } 0.3+\text { D-CER } \\
\text { NS(C16) } 0.3 \text { /CHOL/FA(C24) }\end{array}$ \\
\hline $\begin{array}{l}\text { D24-NS(C16)- } \\
\text { 0-DFA }\end{array}$ & $\begin{array}{l}\text { [CER EOS(C30) } 0.4+\text { D-CER NS(C24) 0.6]/CHOL/ } \\
\text { DFA(C24) }\end{array}$ \\
\hline $\begin{array}{l}\text { D24-NS(C16)- } \\
\text { 50-DFA }\end{array}$ & $\begin{array}{l}\text { [CER EOS(C30) } 0.4+\text { D-CER NS(C24) } 0.3+\text { CER } \\
\text { NS(C16) } 0.3] / \text { CHOL/DFA(C24) }\end{array}$ \\
\hline $\begin{array}{l}\text { D16-NS(C16)- } \\
\text { 50-DFA }\end{array}$ & $\begin{array}{l}\text { [CER EOS(C30) } 0.4+\text { CER NS(C24) } 0.3+\text { D-CER } \\
\text { NS(C16) } 0.3] / \text { CHOL/DFA(C24) }\end{array}$ \\
\hline
\end{tabular}



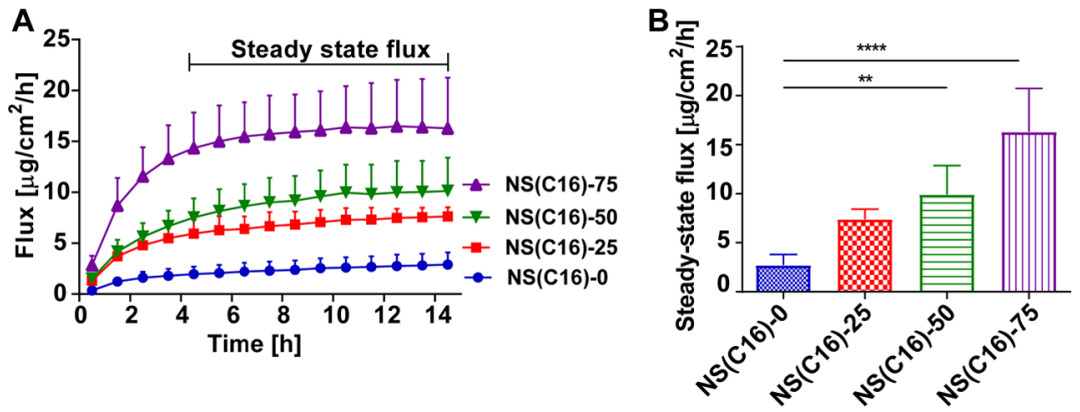

Figure 1. Permeability of the model membranes. (A) Flux of E-PABA across the model membranes over $15 \mathrm{~h}$. The average steady-state flux of EPABA was calculated from the flux values between 10 and $15 \mathrm{~h}$. (B) Average steady-state flux values. Data presented in both plots are the mean values $\pm \mathrm{SD}, n \geq 3$. E-PABA steady-state flux was significantly higher in NS(C16)-50 and NS(C16)-75 compared to that of NS(C16)-0 (control); $* *(P<0.01)$ and $* * * *(P<0.0001)$.

suffix to the model name. Next, a set of models were prepared in which the fatty acid chain of CER NS(C24)/CER NS(C16) in NS(C16)-50 was substituted with the deuterated chain resulting in the models identified by the prefix D24/16-NS. Finally, both CER NS (C24)/CER NS (C16) acyl chain and FA(C24) in NS(C16)-50 were deuterated resulting in the next set of models denoted by D24/16-NS as prefix and DFA as the suffix. The composition of the models used in the present study is shown in Table 1 .

Permeability Studies. To prepare the model mixtures for permeability studies, the proper amount of the required lipids amounting to $0.9 \mathrm{mg}$ were dissolved in hexane/ethanol (2:1) to a concentration of $4.5 \mathrm{mg} / \mathrm{mL}$. Using a Linomat IV device, the solution was sprayed at a rate of $14 \mu \mathrm{L} / \mathrm{s}$ on nucleopore polycarbonate membranes over an area of $10 \times 10 \mathrm{~mm}^{2}$, under a gentle flow of nitrogen, resulting in an $\sim 12 \mu \mathrm{m}$ thick lipid layer. ${ }^{44}$ The samples were equilibrated at $90{ }^{\circ} \mathrm{C}$ for $30 \mathrm{~min}$ and then slowly cooled to room temperature.

In vitro permeation studies were carried out using Permegear inline diffusion cells (Bethlehem PA) with a diffusion area of $0.28 \mathrm{~cm}^{2}$. The model membranes were fixed in the diffusion cells and hydrated for an hour with the acceptor phase, phosphate-buffered saline (PBS $0.1 \mathrm{M}$ solution: $\mathrm{NaCl}, \mathrm{Na}_{2} \mathrm{HPO}_{4}, \mathrm{KH}_{2} \mathrm{PO}_{4}$, and $\mathrm{KCl}$ in Milli-Q water with a concentration of $8.13,1.14,0.20$, and $0.19 \mathrm{~g} / \mathrm{L}$, respectively) at $\mathrm{pH} 7.4$ before the experiment. The PBS was filtered and degassed before use. The donor compartment was filled with $1400 \mu \mathrm{L}$ of a saturated E-PABA $(0.65 \mathrm{mg} / \mathrm{mL})$ in acetate buffer solution $(\mathrm{pH} 5)$. The permeation experiment was performed under occlusive conditions to prevent solvent evaporation. The acceptor phase was perfused at a flow rate of $2 \mathrm{~mL} / \mathrm{h}$. To homogenize the acceptor phase, constant stirring was performed. An in-line degasser was incorporated to trap air bubbles that could obstruct the flow. The temperature of the membranes was kept constant at a skin temperature $\left(32^{\circ} \mathrm{C}\right)$. The acceptor fluid was collected at $1 \mathrm{~h}$ intervals over $15 \mathrm{~h}$. After the diffusion experiment, the volume per collected fraction of the acceptor phase was determined by weighing. Using ultra performance liquid chromatography (UPLC), the concentration of E-PABA was determined. Fick's first law of diffusion was employed for the calculation of E-PABA flux values. ${ }^{46}$ E-PABA steady-state flux values were calculated at time intervals between the 10th and 15th hours. Permeation of several samples of each condition was analyzed $n>3$, where $n$ is the number of repeats.

UPLC Analysis. UPLC was performed using Acquity UPLC systems described previously. ${ }^{50}$ The mobile phase comprised a mixture of $0.1 \%$ trifluoroacetic acid in acetonitrile/Milli-Q water at a 40:60 ( $/ \mathrm{v})$ ratio and the flow rate was $1 \mathrm{~mL} / \mathrm{min}$. The stationary phase comprised a $1.7 \mu \mathrm{m}$ particle-packed column with the temperature set at $40{ }^{\circ} \mathrm{C}$. An injection volume of $10 \mu \mathrm{L}$ was used for the samples and solutions for the calibration curve described previously. ${ }^{49}$ The wavelength of the detector was set at $286 \mathrm{~nm}$, and the data were acquired and processed by MassLynx and TargetLynx software. ${ }^{50}$
Data Analysis. Statistical analysis was performed using GraphPad Prism 7 (GraphPad Software Inc., CA) to analyze the permeability and FTIR data. Statistically significant differences between two groups were determined by two-tailed, unpaired $t$-tests, while differences among groups, with each group compared to a control column, were determined using one-way ANOVA with Dunnett's multiple comparison test. Data are presented as mean \pm standard deviation (SD). Differences in mean are considered statistically significant when $P<0.05$.

FTIR Measurements. An appropriate lipid composition of $1.5 \mathrm{mg}$ was dissolved in chloroform/methanol $(2: 1)$ to a concentration of 5 $\mathrm{mg} / \mathrm{mL}$ and sprayed on a $\mathrm{AgBr}$ window. Spraying was performed using a Linomat IV device (Camag, Muttenz, Switzerland). The solution was sprayed at a rate of $14 \mu \mathrm{L} / \mathrm{s}$, over an area of $10 \times 10$ $\mathrm{mm}^{2}$, under a gentle flow of nitrogen. The samples were equilibrated at $90{ }^{\circ} \mathrm{C}$ for $30 \mathrm{~min}$, ensuring the complete melting of the lipid mixtures, and then slowly cooled to room temperature. The samples were hydrated in deuterated acetate buffer $(\mathrm{pH} 5.0)$ and incubated at $37^{\circ} \mathrm{C}$ for at least $15 \mathrm{~h}$ to ensure that the samples were fully hydrated.

FTIR spectra were acquired with a Varian 670-IR spectrometer (Agilent Technologies, Inc., Santa Clara) equipped with a broad-band mercury cadmium telluride detector. Spectra were collected in transmission mode and generated from 256 co-added interferograms collected over $4 \mathrm{~min}$ at a $1 \mathrm{~cm}^{-1}$ resolution and analyzed using the software Agilent resolution pro (Agilent Technologies, Palo Alto, CA). The sample was kept under a continuous dry air purge, starting 30 min before data collection, and measured over a wavenumber range of $600-4000 \mathrm{~cm}^{-1}$. To determine the phase transitions in relation to the temperature, the spectra were acquired between 0 and $90{ }^{\circ} \mathrm{C}$ at a heating rate of $0.25^{\circ} \mathrm{C} / \mathrm{min}$. Deconvolution of the spectra was executed using a half-width of $4 \mathrm{~cm}^{-1}$, an enhancement factor of 1.6, and was processed with the Agilent resolution pro (Agilent Technologies, Palo Alto, CA). Due to a closely overlapping peak, the enhancement factor was adjusted to 1.2 in the range of the rocking frequencies. To evaluate the conformational disordering and lateral organization, five different regions of specific vibrations on the infrared spectrum were analyzed: (i) $2840-2860 \mathrm{~cm}^{-1}: \mathrm{CH}_{2}$ symmetric stretching $\left(\nu_{\mathrm{s}} \mathrm{CH}_{2}\right)$; (ii) $2080-2100 \mathrm{~cm}^{-1}: \mathrm{CD}_{2}$ symmetric stretching $\left(\nu_{\mathrm{s}} \mathrm{CD}_{2}\right)$; (iii) $700-750 \mathrm{~cm}^{-1}: \mathrm{CH}_{2}$ rocking mode $\left(\rho \mathrm{CH}_{2}\right)$; (iv) $1455-1480 \mathrm{~cm}^{-1}: \mathrm{CH}_{2}$ scissoring mode $\left(\delta \mathrm{CH}_{2}\right)$; and (v) $1080-$ $1096 \mathrm{~cm}^{-1}: \mathrm{CD}_{2}$ scissoring mode $\left(\delta \mathrm{CD}_{2}\right)$. Using the linear regression curve fitting method, the mid-transition temperature was determined as described previously. ${ }^{66}$ Each composition was measured $(n>2)$.

SAXD Studies. SAXD was employed to examine the lamellar organization. To prepare the mixtures, $0.9 \mathrm{mg}$ of the required lipid composition was dissolved in hexane/ethanol (2:1) to a concentration of $4.5 \mathrm{mg} / \mathrm{mL}$. The lipid solution was sprayed over an area of $1 \times 3$ $\mathrm{mm}^{2}$ on a nucleopore polycarbonate membrane under a gentle flow of nitrogen at a rate of $14 \mu \mathrm{L} / \mathrm{s}$ using a Linomat IV device (Camag, Muttenz, Switzerland). The samples were equilibrated at $90{ }^{\circ} \mathrm{C}$ for 30 min, ensuring the complete melting of the lipid mixtures, and then slowly cooled to room temperature. The samples were hydrated in an 
Table 2. E-PABA Steady-State Flux across the Model Membranes, the LPP Repeat Distance, the Midpoint Temperatures of the Orthorhombic-Hexagonal Phase Transition $\left(T_{M, O R-H E X}\right)$, the Ratio of the $730-720 \mathrm{~cm}^{-1}$ Rocking Peak Intensity, and the Length of the $\delta \mathrm{CD}_{2}$ Mode Peak Splitting $\left(\mathrm{cm}^{-1}\right)^{a}$

\begin{tabular}{|c|c|c|c|c|c|c|}
\hline $\begin{array}{l}\text { lipid model (fully } \\
\text { protiated) }\end{array}$ & $\begin{array}{l}\text { steady-state flux } \\
\left(\mu \mathrm{g} / \mathrm{cm}^{2} / \mathrm{h}\right)\end{array}$ & $\begin{array}{c}\text { LPP repeat } \\
\text { distance }(\mathrm{nm})\end{array}$ & 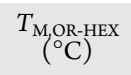 & $\begin{array}{c}730: 720 \mathrm{~cm}^{-1} \text { peak } \\
\text { intensity ratio }\left(10^{\circ} \mathrm{C}\right)\end{array}$ & $\begin{array}{c}730: 720 \mathrm{~cm}^{-1} \text { peak } \\
\text { intensity ratio }\left(32{ }^{\circ} \mathrm{C}\right)\end{array}$ & $\begin{array}{c}\delta \mathrm{CD}_{2} \text { mode peak splitting } \\
\text { distance }\left(\mathrm{cm}^{-1}\right)\end{array}$ \\
\hline NS(C16)-0 & $2.7 \pm 1.1$ & $12.7 \pm 0.0$ & $35.6 \pm 1.1$ & $0.67 \pm 0.08$ & $0.53 \pm 0.07$ & $3.4 \pm 0.2$ \\
\hline $\mathrm{NS}(\mathrm{C} 16)-25$ & $7.3 \pm 1.0$ & $12.8 \pm 0.1$ & $37.2 \pm 1.2$ & $0.53 \pm 0.08$ & $0.40 \pm 0.10$ & $4.1 \pm 0.2$ \\
\hline NS(C16)-50 & $9.9 \pm 2.9$ & $13.0 \pm 0.0$ & $38.9 \pm 0.5$ & $0.48 \pm 0.14$ & $0.36 \pm 0.17$ & $4.5 \pm 0.2$ \\
\hline NS (C16)-75 & $16.3 \pm 4.4$ & $13.5 \pm 0.0$ & $39.1 \pm 1.3$ & $0.44 \pm 0.06$ & $0.30 \pm 0.12$ & $6.7 \pm 0.5$ \\
\hline
\end{tabular}

$\mathrm{FA}(\mathrm{C} 24)$

$0.92 \pm 0.05$

${ }^{a}$ The $\delta \mathrm{CD}_{2}$ mode's peak splitting distance was obtained from the counterparts of the fully protiated models with the FA chains deuterated (-DFA). The error was calculated as the SD.
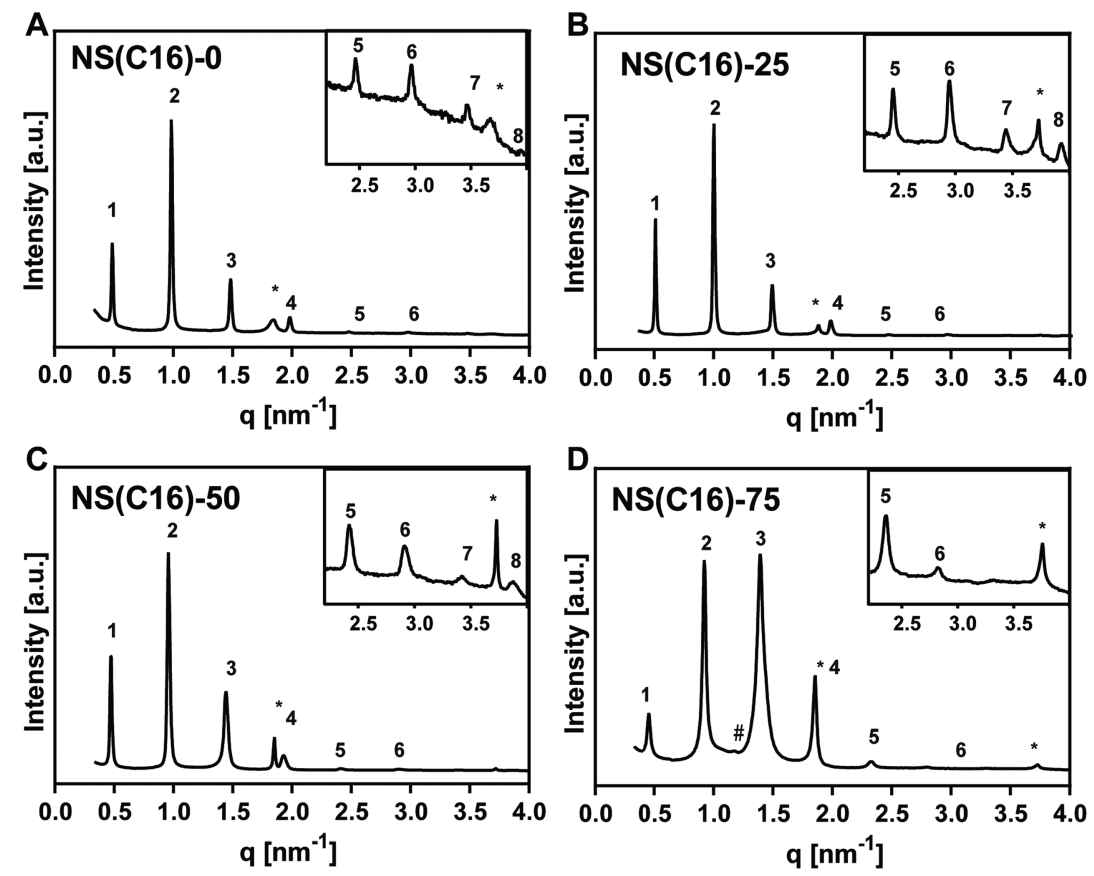

Figure 2. X-ray diffraction profile of the lipid models. The arabic numbers 1-8 indicate the diffraction orders of the LPP. (A) Repeat distance of the LPP in NS $(\mathrm{C} 16)$ is $12.7 \pm 0.04 \mathrm{~nm}$, which is calculated from the reflections at $q=0.50,1.00,1.49,1.99,2.50,3.00,3.49$, and $3.97 \mathrm{~nm}^{-1}$. This represents the 1st to 8th diffraction orders, respectively. (B) Repeat distance of the LPP in NS(C16)-25 is $12.8 \pm 0.05 \mathrm{~nm}$, calculated from the reflections at $q=0.49,0.99,1.48,1.97,2.46,2.97,3.46$, and $3.94 \mathrm{~nm}^{-1}$. This represents the 1st to 8th diffraction orders, respectively. (C) Repeat distance of the LPP in NS(C16)-50 is $13.0 \pm 0.0 \mathrm{~nm}$, calculated from the reflection at $q=0.48,0.97,1.45,1.94,2.41,2.90,3.39$, and $3.85 \mathrm{~nm}^{-1}$. This represents the 1st to 8th diffraction orders, respectively. (D) Repeat distance of the LPP in the NS(C16)-75 model is $13.5 \pm 0.03 \mathrm{~nm}$, calculated from the reflections at $q=0.46,0.93,1.39,1.86,2.33$, and $2.80 \mathrm{~nm}^{-1}$. This represents the 1st to 6th diffraction orders, respectively. The low-intensity peak designated by \# positioned at $q=1.2 \mathrm{~nm}^{-1}$ in the diffraction profile of NS(C16)-75 might be attributed to phase-separated FA(C24). The reflections at $q=1.85 \mathrm{~nm}^{-1}$ indicated by $*$ in all of the models are attributed to phase-separated CHOL and are at the same position as the fourth-order diffraction peak in the diffraction profile of $\mathrm{NS}(\mathrm{C} 16)-75$.

oxygen-free, $84 \%$ relative humidity environment for 5 days at room temperature prior to data acquisition.

The SAXD measurements were undertaken at the NCD-SWEET beamline at the ALBA synchrotron (Barcelona, Spain). The X-ray wavelength $(\lambda)$ and the sample-to-detector distances were $0.999 \AA$ and $2.148 \mathrm{~m}$, respectively. The diffraction patterns were collected using a Pilatus $1 \mathrm{M}$ detector that had a pixel array of $981 \times 1043$, with each pixel being $172 \times 172 \mu \mathrm{m}^{2}$. Silver behenate was used for the calibration of the detector. The samples were measured for $20 \mathrm{~s}$ at 23 ${ }^{\circ} \mathrm{C}$. X-ray intensity scattered by the sample $(I)$ was measured as a function of the scattering vector $(q)$, which is proportional to the angle of scattering $(\theta)$ according to the equation $q=\frac{4 \pi \sin \theta}{\lambda}$. A lamellar phase is identified by a series of peaks with the same interpeak distance. The repeat distance $(d)$ of the lamellar phase was determined from the peak positions using the equation $d=\frac{2 h \pi}{q_{h}}$. The order of the diffraction peak is denoted by $h$. The one-dimensional intensity profiles were integrated from the beam center over a $90^{\circ}$ segment, centered at the beam center. The peak parameters were obtained from the SAXD patterns, fitted with a Pearson 7 function in the software Fityk. ${ }^{67}$ Each composition was measured $(n>2)$.

\section{RESULTS AND DISCUSSION}

Permeability of the Model Membrane Increases with the Proportion of Short-Chain CERs. To evaluate the impact of the increasing proportion of short acyl chain length CERs on barrier function, we examined the effect of the gradual substitution of CER NS(C24) by CER NS(C16) on the permeability of the SC model membrane. In vitro permeation studies were performed with E-PABA as the model drug. The plot of E-PABA flux values for the various membranes is displayed in Figure 1A, while the average steadystate flux values are presented in Table 2 . The average steady- 

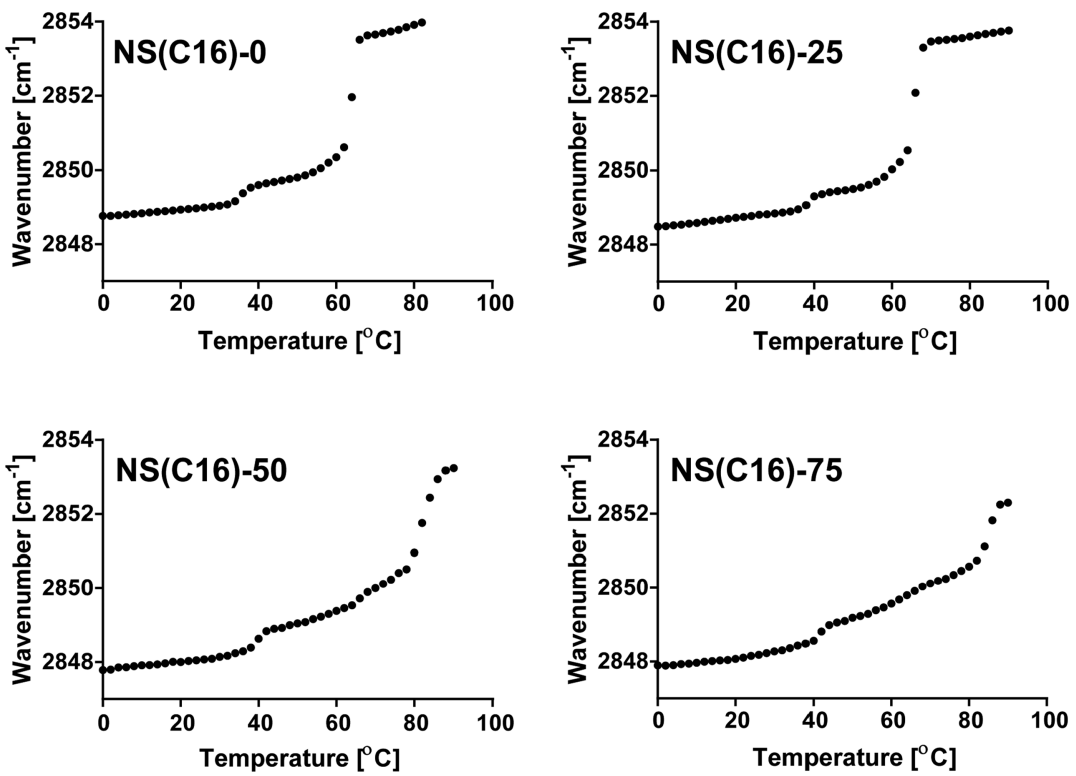

Figure 3. Temperature dependence of the $\nu_{\mathrm{s}} \mathrm{CH}_{2}$ mode frequency of the lipid mixtures. The $\mathrm{v}_{\mathrm{s}} \mathrm{CH}_{2}$ modes of all models between 0 and $90{ }^{\circ} \mathrm{C}$, showing initial frequencies below $2850 \mathrm{~cm}^{-1}$ and two distinct phase transitions as temperature increases. Depending on the composition, $T_{\mathrm{M}, \mathrm{OR}-\mathrm{HEX}}$ was between 34 and $44{ }^{\circ} \mathrm{C}$ and $T_{M, H E X-L I Q}$ was between 60 and $86^{\circ} \mathrm{C}$.

state E-PABA flux was lowest across the control model NS(C16)-0, indicating good barrier capability. As the proportion of short-chain CER NS(C16) was increased at the expense of CER NS(C24), the permeability of the model membrane gradually increased. NS(C16)-50 and NS(C16)-75 E-PABA flux values were significantly higher than that of the control, being $\sim 3.5$ and 6 times higher, respectively (Figure 1B).

In our previous study using a complex SC model mimicking the CER composition of the native human skin, partial substitution of CER NS(C24) with CER NS(C16), which constituted $13 \%$ of the total CER fraction, did not result in a significant increase in permeability. ${ }^{68}$ Interestingly, the simple SC model, NS(C16)-25 in which CER NS(C16) constituted $15 \%$ of the total CER fraction (Table 2), also did not lead to a significant increase in permeability compared with the control. Another study reported that in an SC model membrane containing CER NS of varying acyl chain lengths (C2-C24), the entire substitution of $\mathrm{C} 24$ with $\mathrm{C} 4$ or $\mathrm{C} 6 \mathrm{CER}$ resulted in a significant increase in permeability, while no significant difference was obtained with $\mathrm{C} 2, \mathrm{C} 8, \mathrm{C} 12$, or C18 CER substitution. ${ }^{53}$ In another report, SC models prepared with CER NS(C16) were significantly more permeable than their counterparts containing CER NS(C24) ${ }^{54}$ However, there was a $100 \%$ substitution from CER NS(C24) to CER NS(C16) and an absence of CER EOS in these models and thus no formation of the LPP, which is characteristic of the lipid organization in the skin barrier. Our findings show that an increased level of CER C34, which correlated with an increase in transepidermal water loss (TEWL) in $\mathrm{AD}$ patients' skin, probably contributed to the barrier dysfunction. ${ }^{31,34}$ Our results further showed that the proportion of short-chain CERs at the expense of CER NS(C24) dictated the extent of barrier dysfunction in our model systems.

Increasing Proportion of Short-Chain CERs Results in an Altered Lamellar Organization. Since the lipid organization of the SC intercellular lipid matrix is important for the skin barrier function, we utilized the SAXD technique to provide information about large structural units, including the repeat distances of the lamellar phases in our models. The $\mathrm{X}$-ray diffraction profiles of the lipid mixtures are displayed in Figure 2, while the repeat distances are presented in Table 2. All of the models formed predominantly the LPP attributed to the high content of CER EOS. This is in agreement with previously investigated model lipid mixtures containing 30\% CER EOS and higher. ${ }^{48-51,64,65,69-71}$ The LPP repeat distance increased with the proportion of CER NS(C16). The diffraction profile of NS(C16)-75 differed remarkably from the control. Besides the increased LPP repeat distance, the third-order peak in NS(C16)-75 was broad, especially at the base, and had a higher intensity than the second-order peak, thereby deviating from the characteristic LPP intensity distribution of the diffraction peaks. ${ }^{49,72}$ This may indicate an additional structure with a first-order peak at a similar peak position as the LPPs third-order peak. The presence of phaseseparated lipids is also indicated by the small peak positioned at $q=1.2 \mathrm{~nm}^{-1}$ denoted by \#. This peak may be attributed to the first-order diffraction = peak of pure $\mathrm{FA}(\mathrm{C} 24)$ by virtue of its position (Figure S2). The additional phases in the diffraction profile of NS(C16)-75 may contain CER NS(C16), which would result in a higher concentration of CER EOS within the LPP, explaining the increased repeat distance in NS(C16)-75: a recent study showed that the LPP repeat distance increased with the CER EOS concentration. ${ }^{50}$ All SAXD profiles revealed the presence of a peak $q=1.85 \mathrm{~nm}^{-1}$ attributed to crystalline domains of phase-separated CHOL. In the NS(C16)-75 model, the fourth-order and CHOL are at the same position and thus probably overlapping.

Increased Level of Short-Chain CERs Increases the Phase Transition Temperatures in the Lipid Models. To investigate the reason for the increased permeability of the model membranes with increasing levels of short-chain CER NS(C16), we also examined the lateral lipid organization in the various models. Information about the conformational ordering and phase transition of lipid chains is provided by the position of the $\nu_{\mathrm{s}} \mathrm{CH}_{2}$ frequencies in the infrared spectrum. ${ }^{73}$ 

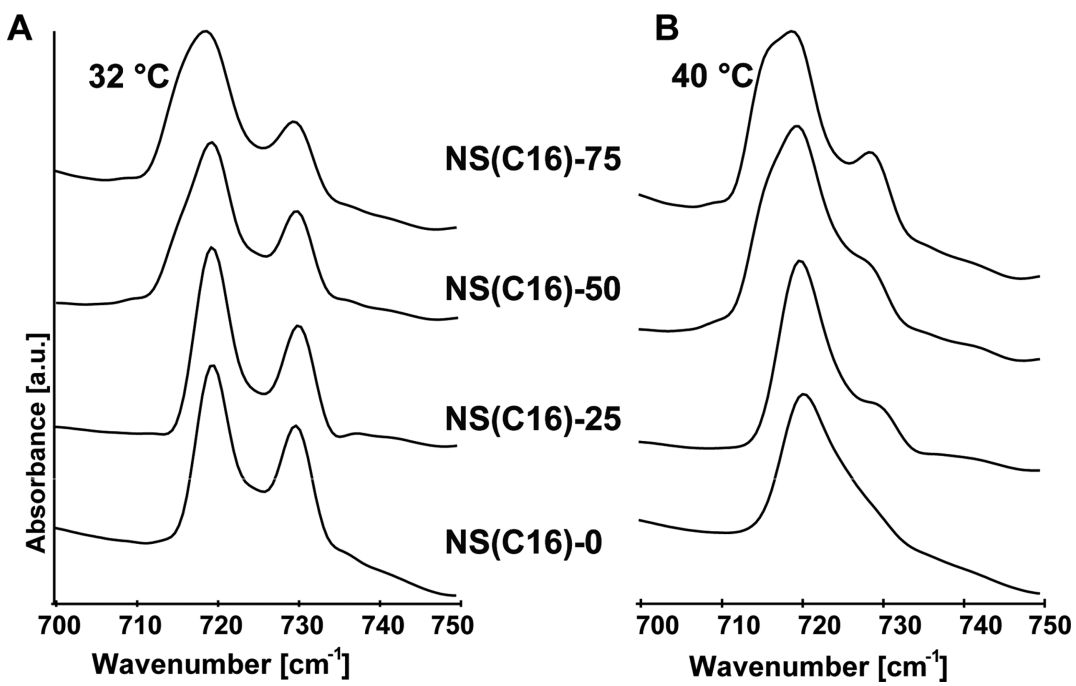

Figure 4. $\rho \mathrm{CH}_{2}$ mode of the fully protiated models. The curves at $(\mathrm{A}) 32{ }^{\circ} \mathrm{C}$ display two distinct bands positioned at approximately 730 and 720 $\mathrm{cm}^{-1}$. (B) $40{ }^{\circ} \mathrm{C}$, NS(C16)-75 $\rho \mathrm{CH}_{2}$ mode displays a prominent $730 \mathrm{~cm}^{-1}$ indicating a thermostable orthorhombic phase. All curves are stacked.
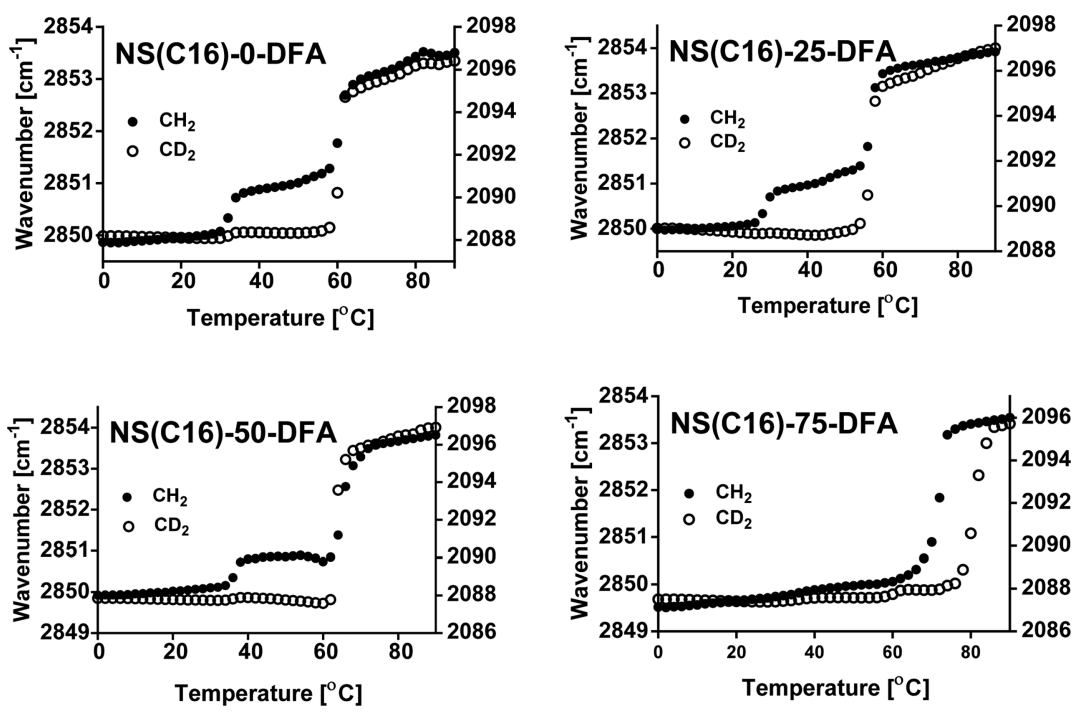

Figure 5. Thermotropic response of the $\nu_{\mathrm{s}} \mathrm{CH}_{2}$ and $\nu_{\mathrm{s}} \mathrm{CD}_{2}$ modes of the lipid models. The $\mathrm{CH}_{2}$ (filled circle) and the $\mathrm{CD}_{2}$ (open circle) peak positions are plotted on the primary $y$-axis and secondary $y$-axis, respectively, displaying the phase transition temperatures of the CERs and DFA(C24) in the lipid models.

Figure 3 shows the thermotropic behavior of $\nu_{\mathrm{s}} \mathrm{CH}_{2}$ vibration. At $10{ }^{\circ} \mathrm{C}$, the $\nu_{\mathrm{s}} \mathrm{CH}_{2}$ frequencies in all of the models appeared at a low wavenumber, below $2850 \mathrm{~cm}^{-1}$, indicating that the lipid chains are ordered. ${ }^{73,74}$ As the temperature increased, a gradual increase in the wavenumber of the stretching vibration by approximately $1 \mathrm{~cm}^{-1}$ was observed between 34 and $44{ }^{\circ} \mathrm{C}$ representing orthorhombic-hexagonal phase transition. The mid-temperature of the transition $\left(T_{\mathrm{M}, \mathrm{OR}-\mathrm{HEX}}\right)$ obtained for the various models is presented in Table 2. $T_{\text {M,OR-HEX }}$ increased with the increase of the proportion of CER NS(C16). $T_{\mathrm{M}, \mathrm{OR}-\mathrm{HEX}}$ for NS(C16)-50 and NS(C16)-75 were significantly higher than that of the control model.

A further temperature increase encountered a second major transition from an ordered to disordered phase, indicated by a large wavenumber increase of $3-4 \mathrm{~cm}^{-1}$ observed in the $\nu_{\mathrm{s}} \mathrm{CH}_{2}$ curves of the various models. The lipid chains in NS(C16)-0 and $\mathrm{NS}(\mathrm{C} 16)-25$ melted over a narrow temperature range from $\sim 60$ to $68{ }^{\circ} \mathrm{C}$. In contrast, NS(C16)-50 and NS(C16)-75 melted in two steps, with a wider transition that started at $\sim 66$ and completed at around $86{ }^{\circ} \mathrm{C}$. The multiple steps suggest the melting of multiple phases. Although the transition temperature of CERs increased with a longer acyl chain, ${ }^{75}$ increasing the level of short-chain CERs in the lipid model shifted the phase transitions of the lipid chains toward higher values in the present study. The mismatch of the short and long acyl chains is expected to influence the packing and mixing of the CERs with CHOL and/or FFA.

Packing Density of Lipid Chains Reduces as the Level of Short-Chain CERs Increases. The packing density of lipid chains is important for the skin barrier function. ${ }^{46,47,62,76}$ Analysis of the $\rho \mathrm{CH}_{2}$ modes of the infrared spectrum reveals the chain-packing properties in lipid mixtures. A hexagonal lateral organization is characterized by a single peak positioned at $\sim 720 \mathrm{~cm}^{-1}$, while the presence of two peaks positioned at $\sim 720$ and $730 \mathrm{~cm}^{-1}$ indicates that the lipid chains are packed in the more dense orthorhombic lattice. ${ }^{77,78}$ The $\rho \mathrm{CH}_{2}$ peaks at 10 and $32{ }^{\circ} \mathrm{C}$ for all of the investigated systems are split into two strong peaks positioned at $\sim 720$ and $730 \mathrm{~cm}^{-1}$. The 
modes at $32{ }^{\circ} \mathrm{C}$ are shown in Figure 4A. The ratio of the intensity of the peaks at 730 and $720 \mathrm{~cm}^{-1}$ is an indication of the proportion of lipids adopting an orthorhombic phase. ${ }^{79,80}$ The $730: 720 \mathrm{~cm}^{-1}$ peak intensity ratio for the models is presented in Table 2 . At $10{ }^{\circ} \mathrm{C}$, the ratio was significantly lower in NS(C16)-50 and NS(C16)-75 compared with that of the control $(P<0.05)$, indicating that a lower proportion of the lipids packs in the orthorhombic phase.

Though primarily orthorhombic, the coexistence of the hexagonal phase cannot be ruled out from the lipid lateral organization in the control model. To examine this, we compared the $\rho \mathrm{CH}_{2}$ mode of $\mathrm{FA}(\mathrm{C} 24)$ at $10{ }^{\circ} \mathrm{C}$, representing the interaction in a system with chains adopting solely orthorhombic packing, ${ }^{80,81}$ with that of the control, NS(C16)-0. In the $\mathrm{FA}(\mathrm{C} 24) \rho \mathrm{CH}_{2}$ mode, the $730: 720 \mathrm{~cm}^{-1}$ peak intensity ratio was practically equal to 1 , characterizing a purely orthorhombic system. In contrast, NS(C16)-0, the $730 \mathrm{~cm}^{-1}$ peak was less intense than the $720 \mathrm{~cm}^{-1}$ peak $(\sim 0.70)$, indicating that a small fraction of the lipids adopts the hexagonal phase at the expense of the orthorhombic phase. The slight reduction in the $730: 720 \mathrm{~cm}^{-1}$ peak intensity ratio at $32{ }^{\circ} \mathrm{C}$ in all of the models indicates a gradual reduction in the proportion of the orthorhombic phase with increasing temperature. Though of lower proportion, the NS(C16)-75 orthorhombic phase was more thermostable than that of the control indicated by the prominent $730 \mathrm{~cm}^{-1}$ peak still present at $40{ }^{\circ} \mathrm{C}$ (Figure 4B), suggesting some phase separation. This may explain why the $T_{\mathrm{M}, \mathrm{OR}-\mathrm{HEX}}$ was higher as CER NS(C16) content increased. Though several studies have shown a direct relationship between the proportion of the orthorhombic phase and barrier function, ${ }^{46,47,76}$ other factors may also play a role here.

Short-Chain CERs Reduce the Miscibility of CERs and FFA Chains. In a lipid mixture, selective chain deuteration allows for the behavior of different chains to be monitored separately within the same experiment. The vibrations of the methylene chain (protiated) and the deuterated counterpart occur at different regions in the infrared spectrum. ${ }^{80} \mathrm{We}$ analyzed the $\nu_{\mathrm{s}} \mathrm{CH}_{2}$ vibrations from the CER chains and $\nu_{\mathrm{s}} \mathrm{CD}_{2}$ vibrations from the deuterated $\mathrm{FA}(\mathrm{C} 24)$. The plot of the thermotropic response of the $\nu_{\mathrm{s}} \mathrm{CH}_{2}$ and $\nu_{\mathrm{s}} \mathrm{CD}_{2}$ vibrations is displayed in Figure 5. The CERs and FA(C24) chains undergo an order-disorder phase transition at the same temperature range in NS(C16)-0-DFA, NS(C16)-25-DFA, and NS(C16)50-DFA. Therefore, considering the stretching frequencies, there is no indication that the CER and FFA chains in these models phase-separate. In contrast, the CERs and FA(C24) chains in NS(C16)-75-DFA did not melt simultaneously, but the FA(C24) melted at temperatures $\sim 12{ }^{\circ} \mathrm{C}$ higher than the CER chains, indicating segregation of the two lipid classes. Furthermore, the melting of the FA chains in NS(C16)-75DFA was sharp and occurred between 80 and $86{ }^{\circ} \mathrm{C}$, which is in the same temperature range as the melting of pure DFA(C24) (see Figure S3). Regarding the $\nu_{\mathrm{s}} \mathrm{CH}_{2}$ curves, as CERs and $\mathrm{CHOL}$ are protiated, the absence of noticeable phase transition from orthorhombic to hexagonal in the NS(C16)-75-DFA $\nu_{s} \mathrm{CH}_{2}$ thermotropic response curve strongly indicates phase separation between CERs and FFA since in general the addition of FFA to mixtures with CERs and CHOL induces an orthorhombic packing. ${ }^{82}$

We analyzed the miscibility of the CERs and FA chains in more detail using the scissoring vibrations. When CER chains and deuterated FFA chains are mixed in an orthorhombic lattice, adjacent protiated CER and deuterated FFA chains cannot engage in short-range coupling due to the differences in vibrational energy. ${ }^{81}$ As a consequence, the peak splitting, observed when chains from the same isotope are neighboring each other, is eliminated. ${ }^{80}$ Thus, a single peak is displayed in the $\delta \mathrm{CD}_{2}$ and $\delta \mathrm{CH}_{2}$ modes. A plot of the $\delta \mathrm{CD}_{2}$ modes of the various models and pure $\mathrm{DFA}(\mathrm{C} 24)$ mixture at 10 and $32{ }^{\circ} \mathrm{C}$ are displayed in Figure $6 \mathrm{~A}, \mathrm{~B}$, respectively. At $10{ }^{\circ} \mathrm{C}$, the $\delta \mathrm{CD}_{2}$

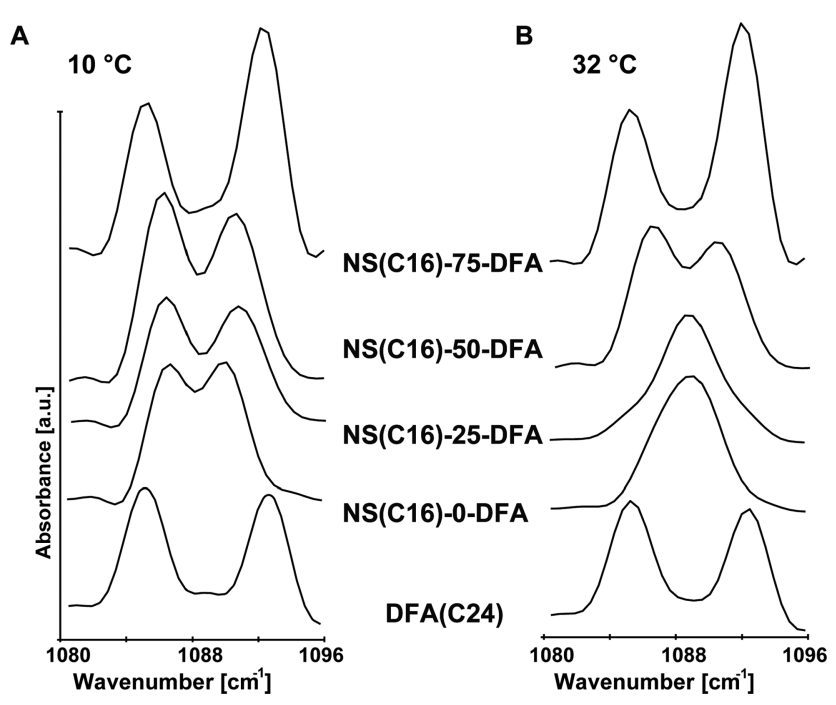

Figure 6. $\delta \mathrm{CD}_{2}$ modes of the lipid models with $\mathrm{FA}(\mathrm{C} 24)$ chain deuterated. The $\delta \mathrm{CD}_{2}$ curves of the different lipid models at (A) 10 ${ }^{\circ} \mathrm{C}(\mathrm{B})$ and $32{ }^{\circ} \mathrm{C}$.

bands in all models are split into two components. The size of the orthorhombic domain formed by the deuterated lipids was analyzed by measuring the magnitude of peak splitting. ${ }^{81} \mathrm{~A}$ larger split corresponds to a larger domain size. ${ }^{83}$

The splitting values are reported in Table 2 . The splitting length increases with an increasing proportion of short-chain CER NS(C16). The splitting length was small in NS(C16)-0DFA and NS(C16)-25-DFA, indicating a limited interaction of deuterated chains and thus mixing of the protiated and deuterated chains, while the larger splitting value is measured in NS(C16)-50-DFA with a strong increase in NS(C16)-75DFA. The latter approaches the maximum value as seen in pure DFA(C24) with a splitting distance of $7.5 \mathrm{~cm}^{-1}$. This suggests the presence of large $\operatorname{DFA}(\mathrm{C} 24)$-rich domains. The extensive miscibility of the control model is attributed to an optimized hydrophobic match between FA(C24) with CER NS(C24) leading to strong van der Waals interchain interaction. Miscibility of the CERs and the DFA(C24) chains reduced with an increasing proportion of CER NS(C16). At 32 ${ }^{\circ} \mathrm{C}$, the $\delta \mathrm{CD}_{2}$ modes of NS(C16)-0-DFA and NS(C16)-25DFA collapsed into single peaks, while those of NS(C16)-50DFA and NS(C16)-75-DFA remained split, collapsing into single peaks at 38 and $84{ }^{\circ} \mathrm{C}$, respectively (Figure S4A,B). The split of the NS(C16)-75-DFA $\delta \mathrm{CD}_{2}$ mode collapsed at the melting temperature of pure $\operatorname{DFA}(\mathrm{C} 24)$, indicating the presence of separate large crystalline domains containing pure DFA. The existence of phase-separated FA(C24) is also shown by the presence of an additional peak in the SAXD pattern of NS(C16)-75. Probably, phase separation of FFA contributed to the increased permeability of NS(C16)-75.

Short-Chain CERs Are Less Ordered than Long-Chain CERs in SC Models. To gain more insight into the effect of 

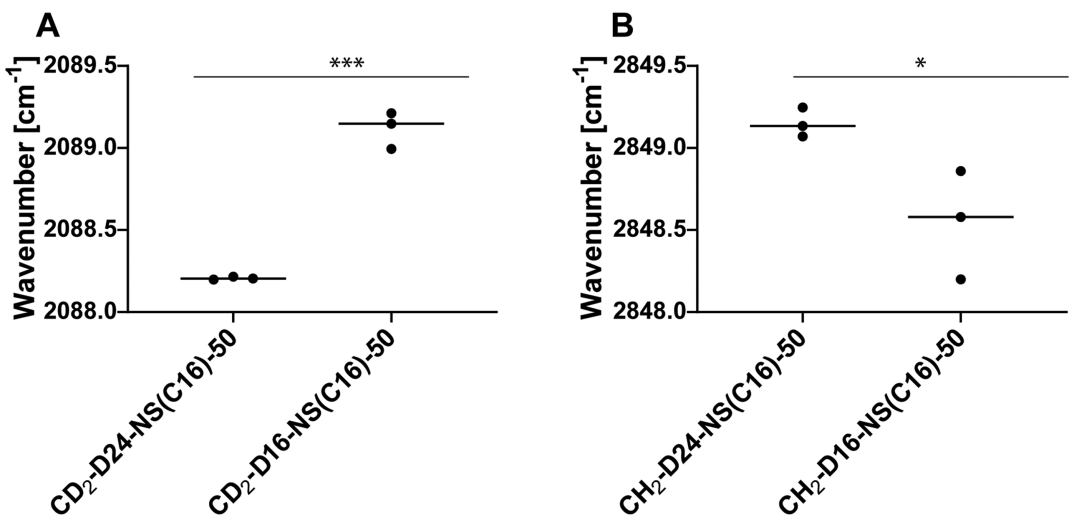

Figure 7. Thermotropic response of NS(C16)-50 $\nu_{s} \mathrm{CH}_{2}$ and $\nu_{\mathrm{s}} \mathrm{CD}_{2}$ frequencies when either $\mathrm{C} 16$ or $\mathrm{C} 24$ chains are deuterated and the wavenumbers at $10{ }^{\circ} \mathrm{C}$. (A) Wavenumbers at $10{ }^{\circ} \mathrm{C}$ for $\mathrm{CD}_{2}$-D24-NS(C16)-50 and $\mathrm{CD}_{2}$-D16-NS(C16)-50, with $\mathrm{C} 24$ and $\mathrm{C} 16$ acyl chains deuterated, respectively. The wavenumber of the CER NS(C16) chain is significantly higher than that of the CER NS(C24) chain. (B) Wavenumbers at $10{ }^{\circ} \mathrm{C}$ for $\mathrm{CH}_{2}-\mathrm{D} 24-\mathrm{NS}(\mathrm{C} 16)-50$ (arising from protiated chains when only NS(C24) acyl chains are deuterated) and $\mathrm{CH}_{2}-\mathrm{D} 16-$ NS(C16)-50 modes (arising from protiated chains when only NS(16) acyl chains are deuterated). Wavenumber of $\mathrm{CH}_{2}-\mathrm{D} 24-\mathrm{NS}(\mathrm{C} 16)-50$ containing the protiated CER NS(C16) chain is significantly higher than that of the $\mathrm{CH}_{2}$-D16-NS(C16)-50 mode in which CER NS(C24) chains were protiated.

the different CER NS chain lengths on the phase behavior of the SC model, either the C24 or C16 acyl chains in NS(C16)50 , which contain equal proportions of CERs NS (C24) and (C16), were selectively deuterated. The detailed compositions of D24-NS(C16)-50 and D16-NS(C16)-50 are presented in Table 1 , while their corresponding $\nu_{\mathrm{s}} \mathrm{CH}_{2}$ and $\nu_{\mathrm{s}} \mathrm{CD}_{2}$ modes at $10{ }^{\circ} \mathrm{C}$ are displayed in Figure $7 \mathrm{~A}, \mathrm{~B}$, respectively. The $\nu_{\mathrm{s}} \mathrm{CH}_{2}$ and $\nu_{\mathrm{s}} \mathrm{CD}_{2}$ modes of the lipid models were well ordered at low temperatures. The $10{ }^{\circ} \mathrm{C}$ wavenumber in the $\nu_{\mathrm{s}} \mathrm{CD}_{2}$ mode of D24-NS(C16)-50 appeared at $2088.2 \pm 0.0 \mathrm{~cm}^{-1}$, while that of D16-NS(C16)-50 appeared at a comparatively higher wavenumber of $2089.1 \pm 0.1 \mathrm{~cm}^{-1}$ (Figure $7 \mathrm{~A}$ ) indicating less conformation by the short-chain CER NS(C16). This is similar to that observed in a previous study with models containing CER composition that mimics that in human skin. ${ }^{68}$ Regarding the $\nu_{\mathrm{s}} \mathrm{CH}_{2}$ modes, the $10{ }^{\circ} \mathrm{C}$ wavenumber of D24-NS(C16)-50 and D16-NS(C16)-50 appeared at 2849.2 \pm 0.1 and $2848.5 \pm$ $0.3 \mathrm{~cm}^{-1}$, respectively, demonstrating highly ordered methylene chains (Figure 7B). The differences in the $\nu_{\mathrm{s}} \mathrm{CH}_{2}$ and $\nu_{\mathrm{s}} \mathrm{CD}_{2}$ modes can be explained by the $\mathrm{C} 16$ acyl chain being in a higher conformational disorder than the $\mathrm{C} 24$ acyl chain. The high mobility of the short-chain CERs in the lipid layers may contribute to the impaired lipid barrier function.

CER NS(C16) and CER NS(C24) Acyl Chains Are Present in the Central and Outer Layers of the LPP. Previous studies reported that the majority of the CER NS (C24) acyl chain and the FA(C24) are colocalized with one another within the central region of the trilayer LPP structure, with CER NS(C24) in an extended conformation, encouraging tighter chain packing, favorable for a proper barrier function $^{65,69,84}$ (Figure 8).

To examine the influence of short-chain CERs on the lipid arrangement within the LPP, we analyzed the interaction in SC lipid models containing an equal proportion of NS(C24) and CER NS(C16) in their CER fraction, with the acyl chain of either CER NS(16) or CER NS(24) and FA(C24) deuterated. These models are referred to as D24-NS(C16)-50-DFA and D16-NS(C16)-50-DFA. As a control model, D24-NS(C16)-0DFA was used. The detailed composition of the models is presented in Table 1 , while their $\delta \mathrm{CD}_{2}$ and $\delta \mathrm{CH}_{2}$ contours are displayed in Figure 9A,B, respectively.

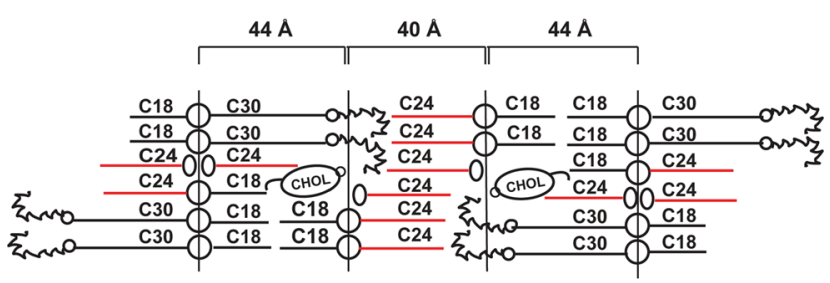

Figure 8. Molecular model proposed for the unit cell of the LPP is based on the determined location of lipids in a neutron diffraction experiment (Mojumdar et al.). ${ }^{69}$ The deuterated acyl chains are marked in red. The ovals, big, and small circles represent the FA headgroups, CER headgroups, and ester linkages, respectively. FA(C24) and CER NS (C24) acyl chains are colocalized in the central layer of the LPP, but smaller fractions are also present in the outer layers with CHOL, CER EOS (C30) acyl chain, and CER EOS and CER NS sphingosine chains. The figure is adapted from Mojumdar et al. ${ }^{69}$

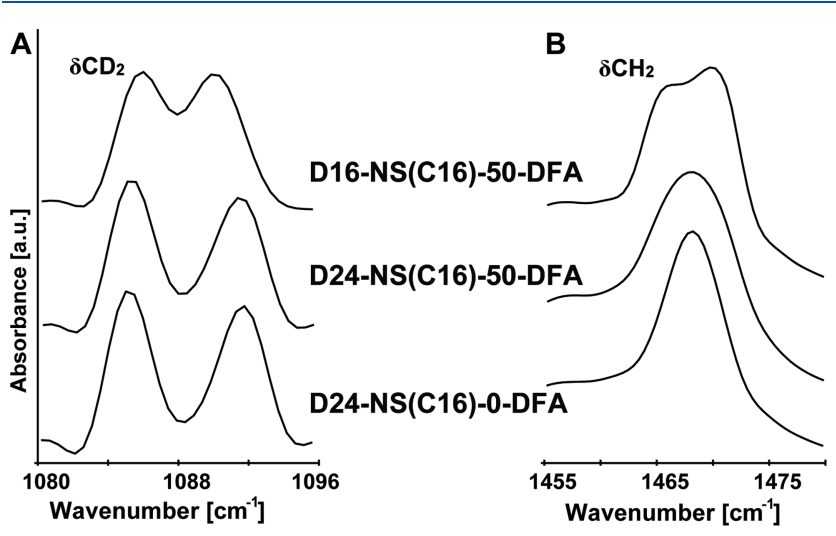

Figure 9. SC models with CER NS acyl chains and FA(C24) chains deuterated at $10{ }^{\circ} \mathrm{C}$. (A) $\delta \mathrm{CD}_{2}$ mode; a strong peak splitting indicates a strong $\mathrm{CD}_{2}-\mathrm{CD}_{2}$ interaction, while weak splitting indicates extensive $\mathrm{CD}_{2}-\mathrm{CH}_{2}$. (B) $\delta \mathrm{CH}_{2}$ modes of the models; single peak implies limited $\mathrm{CH}_{2}-\mathrm{CH}_{2}$ interaction, while the increased peak width indicates a greater $\mathrm{CH}_{2}-\mathrm{CH}_{2}$ interaction.

In control model D24-NS(C16)-0-DFA, the $\delta \mathrm{CD}_{2}$ mode was split into two strong peaks attributed to the interaction of the deuterated CER NS(C24) acyl chain and DFA(C24). A 
large split value of $6.4 \pm 0.1 \mathrm{~cm}^{-1}$ together with a low minimum in between the peaks indicates that there is limited $\mathrm{CH}_{2}-\mathrm{CD}_{2}$ interaction. Thus, the deuterated chains did not interact to a great extent with the protiated components, which include the CER EOS, sphingosine chains of CER NS(C24), and CHOL. Since FA(C24) and CER NS(C24) do not phaseseparate as shown in the partially deuterated mixture (Figure 6), the sphingosine chain and the acyl chain of CER NS (C24) must occupy different positions within the LPP. This is in agreement with an extended arrangement of CER NS, with the acyl and sphingosine chains in different layers of the LPP as reported previously, ${ }^{65,85}$ and is shown in a schematic image of the lipid arrangement in the $\mathrm{LPP}^{69}$ (Figure 8). The $\delta \mathrm{CH}_{2}$ mode of D24-NS(C16)-0-DFA exhibited a single peak suggesting limited interaction between the protiated chains. Though the deuterated FA(C24) and CER NS(C24) acyl chains are located mainly in the middle layer of the LPP, a fraction of the chains was shown to be present in the outer layer of the LPP as well, ${ }^{65,69,85,86}$ probably disrupting the $\mathrm{CH}_{2}-\mathrm{CH}_{2}$ interaction in the boundary layer and inducing the $\mathrm{CH}_{2}-\mathrm{CD}_{2}$ interaction. The $\mathrm{CH}_{2}-\mathrm{CH}_{2}$ interaction might also be limited when lipid chains adopt the less dense hexagonal packing. Though predominantly orthorhombic, the coexistence of a subpopulation of lipids adopting the hexagonal phase in D24-NS(C16)-0-DFA is indicated by the lower $730: 720 \mathrm{~cm}^{-1}$ peak intensity ratio of the fully protiated counterpart NS(C16)-0 compared to that of the fully orthorhombic $\mathrm{FA}(\mathrm{C} 24)$ (Table 2). The single peak observed in the D24$\mathrm{NS}(\mathrm{C} 16)-0$-DFA $\delta \mathrm{CH}_{2}$ mode at $10{ }^{\circ} \mathrm{C}$ is probably due to a combined effect of the presence of hexagonal phase and $\mathrm{FA}(\mathrm{C} 24)$ and CER NS(C24) acyl chains in the outer layer of the LPP.

In D24-NS(C16)-50-DFA, the $\delta \mathrm{CD}_{2}$ vibration arises from the interaction of DFA(C24) and D-CER NS(C24) acyl chains. The $\delta \mathrm{CD}_{2}$ mode displayed a strong splitting measuring $6.1 \pm 0 \mathrm{~cm}^{-1}$, indicating large orthorhombic domains. In the D24-NS(C16)-50-DFA, $\mathrm{CD}_{2}$ peak intensities and splitting length were only slightly less than that in the spectrum of DNS(C16)-0-DFA. This indicates large domains of deuterated lipids, despite the presence of protiated CER NS(C16) in the mixture, which suggests that the NS(C16) acyl chains are not primarily distributed between the deuterated chains of DFA(C24) and D-CER NS(C24) in the central layer of the unit cell of the LPP. As the minimum between the peaks of the $\delta \mathrm{CD}_{2}$ mode is higher than that observed in the spectrum of D24-NS(C16)-0-DFA, there may be some regions with $\mathrm{CH}_{2}-$ $\mathrm{CD}_{2}$ interactions in D24-NS(C16)-50-DFA, which could be attributed to a small fraction of the protiated $\mathrm{C} 16$ acyl chain of CER NS $(\mathrm{C} 16)$ in the LPP's central layer. The $\delta \mathrm{CH}_{2}$ vibrations in D24-NS(C16)-50-DFA arise from CERs NS(C16) and the remaining protiated chains. The $-\mathrm{CH}_{2}$ peak is broader than that of D24-NS(C16)-0-DFA. The presence of a fraction of the CER NS (C16) acyl in the outer layers of the LPP could explain the increased $\mathrm{CH}_{2}-\mathrm{CH}_{2}$ interaction compared to that of the control. An increased $\mathrm{CH}_{2}-\mathrm{CH}_{2}$ interaction could also suggest phase separation. However, this is not likely as neither phase-separated FA(C24) nor CER (NS) C16/C24 domains were detected when the mixing properties of the lipid chains in NS(C24)-50 were monitored by selective deuteration.

The spectrum of the D16-NS(C16)-50-DFA $\delta \mathrm{CD}_{2}$ mode was also split into two peaks. The splitting length, being $4.1 \pm$ $0.1 \mathrm{~cm}^{-1}$, was significantly less than that of D24-NS(C16)-0DFA indicating smaller deuterated chain domains (Figure 9A).
The shallower minimum means a higher proportion of $\mathrm{CH}_{2}-$ $\mathrm{CD}_{2}$ interactions, showing that the protiated $\mathrm{C} 24$ acyl chain of CER NS(C24) mixes more extensively with DFA(C24) than the protiated $\mathrm{C} 16$ acyl chains of $\mathrm{CER}(\mathrm{C} 16)$ with the DFA chains in the D24-NS(C16)-50-DFA. The protiated lipids in D16-NS(C16)-50-DFA include CERs EOS, NS(C24), CHOL, and sphingosine chains of CER NS(C16). The $\mathrm{CH}_{2}$ mode displays two distinct peaks indicating more $\mathrm{CH}_{2}-\mathrm{CH}_{2}$ chain interaction than in D24-NS(C16)-50-DFA and D24-NS(C16)0 -DFA. The increased interaction may result from some protiated NS(C24) chains at the same region with the rest of the protiated chains in the boundary layers of the LPP. This is consistent with the single peak of the protiated chains in the spectrum of the D24-NS(C16)-0-DFA.

\section{CONCLUSIONS}

SC lipid models enabled a detailed examination of the effect of the proportion of the short-chain CER NS(C16) on the permeability of the simple SC model membrane. The weakest barrier was obtained in the SC model when $75 \%$ of the CER NS(24) was substituted with CER NS(C16) resulting in the formation of separate domains, especially FA(C24), as could be deduced from the SAXD and FTIR studies. The proportion of the CER NS(C16) dictated the extent of the variation in lipid organization and barrier dysfunction in the SC model membrane. Relating these findings to the diseased skin, the increased level of short-chain CERs reported in several inflammatory skin diseases including $\mathrm{AD}$ and Netherton syndrome contributes to the impaired barrier function.

Use of deuterated lipids afforded insight into the distribution of the C16 and C24 acyl chains within the trilayer LPP structure. We deduced that in the SC models containing both CER NS(C24) and CER NS(C16) as observed in the diseased skin, the acyl chains of CER NS(C24) and the FA(C24) are mainly colocalized with one another within the central region of the trilayer LPP, while CER NS(C16) acyl chains are not primarily distributed within this middle layer. The findings in the present study contribute to our understanding of the contribution of CER compositional changes to barrier dysfunction in the diseased skin, which is important for targeting treatment.

\section{ASSOCIATED CONTENT}

\section{Supporting Information}

The Supporting Information is available free of charge at https://pubs.acs.org/doi/10.1021/acs.langmuir.1c01295.

Molecular structure of all of the lipids, X-ray diffraction profile of FA (C24), and FTIR spectrum showing the CD2 scissoring vibration curves of DFA (C24) and CERs/CHOL/DFA(C24) mixtures (PDF)

\section{AUTHOR INFORMATION}

\section{Corresponding Author}

Joke A. Bouwstra - Division BioTherapeutics, Leiden Academic Centre for Drug Research, Leiden University, 2333 CC Leiden, Netherlands; ㅇo orcid.org/0000-0002-71236868; Email: bouwstra@chem.leidenuniv.nl

\section{Authors}

Lorretta E. Uche - Division BioTherapeutics, Leiden Academic Centre for Drug Research, Leiden University, 2333 CC Leiden, Netherlands 
Gerrit S. Gooris - Division BioTherapeutics, Leiden Academic Centre for Drug Research, Leiden University, 2333 CC Leiden, Netherlands

Charlotte M. Beddoes - Division BioTherapeutics, Leiden Academic Centre for Drug Research, Leiden University, 2333 CC Leiden, Netherlands; 이이이.org/0000-0001-74491031

Complete contact information is available at: https://pubs.acs.org/10.1021/acs.langmuir.1c01295

\section{Notes}

The authors declare no competing financial interest.

\section{ACKNOWLEDGMENTS}

The authors thank Evonik for donating several ceramide subclasses. The authors also express their gratitude to the ALBA Synchrotron facility for awarding them time on the BL11-NCD-SWEET beamlines and providing assistance with $\mathrm{X}$-ray scattering measurements.

\section{REFERENCES}

(1) Hannun, Y. A. Functions of ceramide in coordinating cellular responses to stress. Science 1996, 274, 1855-1859.

(2) van Blitterswijk, W. J.; van der Luit, A. H.; Veldman, R. J.; Verheij, M.; Borst, J. Ceramide: second messenger or modulator of membrane structure and dynamics? Biochem. J. 2003, 369, 199-211.

(3) Wang, X. Lipid signaling. Curr. Opin. Plant Biol. 2004, 7, 329336.

(4) Taha, T. A.; Mullen, T. D.; Obeid, L. M. A house divided: Ceramide, sphingosine, and sphingosine-1-phosphate in programmed cell death. Biochim. Biophys. Acta, Biomembr. 2006, 1758, 2027-2036.

(5) Kolesnick, R. N.; Goni, F. M.; Alonso, A. Compartmentalization of ceramide signaling: physical foundations and biological effects. J. Cell. Physiol. 2000, 184, 285-300.

(6) Weerheim, A.; Ponec, M. Determination of stratum corneum lipid profile by tape stripping in combination with high-performance thin-layer chromatography. Arch. Dermatol. Res. 2001, 293, 191-199.

(7) Gray, G. M.; Yardley, H. J. Lipid compositions of cells isolated from pig, human, and rat epidermis. J. Lipid Res. 1975, 16, 434-440.

(8) Elias, P. M.; Goerke, J.; Friend, D. S. Mammalian epidermal barrier layer lipids: composition and influence on structure. J. Invest. Dermatol. 1977, 69, 535-546.

(9) Elias, P. M. Epidermal lipids, membranes, and keratinization. Int. J. Dermatol. 1981, 20, 1-19.

(10) Wertz, P. W.; van den Bergh, B. The physical, chemical and functional properties of lipids in the skin and other biological barriers. Chem. Phys. Lipids 1998, 91, 85-96.

(11) Blank, I. H. Cutaneous barriers. J. Invest. Dermatol. 1965, 45, 249-256.

(12) Elias, P. M. Epidermal barrier function - Intercellular lamellar lipid structures, origin, composition, and metabolism. J. Controlled Release 1991, 15, 199-208.

(13) Lee, S. H.; Jeong, S. K.; Ahn, S. K. An update of the defensive barrier function of skin. Yonsei Med. J. 2006, 47, 293-306.

(14) Proksch, E.; Brandner, J. M.; Jensen, J. M. The skin: an indispensable barrier. Exp. Dermatol. 2008, 17, 1063-1072.

(15) Wickett, R. R.; Visscher, M. O. Structure and function of the epidermal barrier. Am. J. Infect. Control 2006, 34, S98-S110.

(16) Feingold, K. R. The role of epidermal lipids in cutaneous permeability barrier homeostasis. J. Lipid Res. 2007, 48, 2531-2546.

(17) Bouwstra, J. A.; Gooris, G. S.; Bras, W.; Downing, D. T. Lipid organization in pig stratum-corneum. J. Lipid Res. 1995, 36, 685-695.

(18) Hill, J. R.; Wertz, P. W. Molecular models of the intercellular lipid lamellae from epidermal stratum corneum. Biochim. Biophys. Acta, Biomembr. 2003, 1616, 121-126.
(19) White, S. H.; Mirejovsky, D.; King, G. I. Structure of lamellar lipid domains and corneocyte envelopes of murine stratum corneum. An X-ray diffraction study. Biochemistry 1988, 27, 3725-3732.

(20) Schmitt, T.; Neubert, R. H. H. State of the art in Stratum Corneum research: The biophysical properties of ceramides. Chem. Phys. Lipids 2018, 216, 91-103.

(21) Masukawa, Y.; Narita, H.; Shimizu, E.; Kondo, N.; Sugai, Y.; Oba, T.; Homma, R.; Ishikawa, J.; Takagi, Y.; Kitahara, T.; Takema, Y.; Kita, K. Characterization of overall ceramide species in human Stratum corneum. J. Lipid Res. 2008, 49, 1466-1476.

(22) Robson, K. J.; Stewart, M. E.; Michelsen, S.; Lazo, N. D.; Downing, D. T. 6-Hydroxy-4-sphingenine in human epidermal ceramides. J. Lipid Res. 1994, 35, 2060-2068.

(23) Stewart, M. E.; Downing, D. T. A new 6-hydroxy-4sphingenine-containing ceramide in human skin. J. Lipid Res. 1999, 40, 1434-1439.

(24) van Smeden, J.; Hoppel, L.; van der Heijden, R.; Hankemeier, T.; Vreeken, R. J.; Bouwstra, J. A. LC/MS analysis of stratum corneum lipids: ceramide profiling and discovery. J. Lipid Res. 2011, 52, 1211-1221.

(25) Rabionet, M.; Gorgas, K.; Sandhoff, R. Ceramide synthesis in the epidermis. Biochim. Biophys. Acta, Mol. Cell Biol. Lipids 2014, 1841, 422-434.

(26) Wertz, P. W.; Miethke, M. C.; Long, S. A.; Strauss, J. S.; Downing, D. T. The Composition of the ceramides from human stratum-corneum and from comedones. J. Invest. Dermatol. 1985, 84, $410-412$.

(27) van Smeden, J.; Bouwstra, J. A. Stratum corneum lipids: Their role for the skin barrier function in healthy subjects and atopic dermatitis patients. Curr. Probl. Dermatol. 2016, 49, 8-26.

(28) t'Kindt, R.; Jorge, L.; Dumont, E.; Couturon, P.; David, F.; Sandra, P.; Sandra, K. Profiling and characterizing skin ceramides using reversed-phase liquid chromatography-quadrupole time-offlight mass spectrometry. Anal. Chem. 2012, 84, 403-411.

(29) Coderch, L.; López, O.; de la Maza, A.; Parra, J. L. Ceramides and Skin Function. Am. J. Clin. Dermatol. 2003, 4, 107-129.

(30) Masukawa, Y.; Narita, H.; Sato, H.; Naoe, A.; Kondo, N.; Sugai, Y.; Oba, T.; Homma, R.; Ishikawa, J.; Takagi, Y.; Kitahara, T. Comprehensive quantification of ceramide species in human stratum corneum. J. Lipid Res. 2009, 50, 1708-1719.

(31) Ishikawa, J.; Narita, H.; Kondo, N.; Hotta, M.; Takagi, Y.; Masukawa, Y.; Kitahara, T.; Takema, Y.; Koyano, S.; Yamazaki, S.; Hatamochi, A. Changes in the ceramide profile of atopic dermatitis patients. J. Invest. Dermatol. 2010, 130, 2511-2514.

(32) Di Nardo, A.; Wertz, P.; Giannetti, A.; Seidenari, S. Ceramide and cholesterol composition of the skin of patients with atopic dermatitis. Acta Derm.-Venereol. 1998, 78, 27-30.

(33) Imokawa, G.; Abe, A.; Jin, K.; Higaki, Y.; Kawashima, M.; Hidano, A. Decreased level of ceramides in stratum corneum of atopic dermatitis: an etiologic factor in atopic dry skin? J. Invest. Dermatol. 1991, 96, 523-526.

(34) Janssens, M.; van Smeden, J.; Gooris, G. S.; Bras, W.; Portale, G.; Caspers, P. J.; Vreeken, R. J.; Hankemeier, T.; Kezic, S.; Wolterbeek, R.; Lavrijsen, A. P.; Bouwstra, J. A. Increase in shortchain ceramides correlates with an altered lipid organization and decreased barrier function in atopic eczema patients. J. Lipid Res. 2012, 53, 2755-2766.

(35) Janssens, M.; van Smeden, J.; Gooris, G. S.; Bras, W.; Portale, G.; Caspers, P. J.; Vreeken, R. J.; Kezic, S.; Lavrijsen, A. P.; Bouwstra, J. A. Lamellar lipid organization and ceramide composition in the stratum corneum of patients with atopic eczema. J. Invest. Dermatol. 2011, 131, 2136-2138.

(36) Motta, S.; Monti, M.; Sesana, S.; Caputo, R.; Carelli, S.; Ghidoni, R. Ceramide composition of the psoriatic scale. Biochim. Biophys. Acta, Mol. Basis Dis. 1993, 1182, 147-151.

(37) van Smeden, J.; Janssens, M.; Boiten, W. A.; van Drongelen, V.; Furio, L.; Vreeken, R. J.; Hovnanian, A.; Bouwstra, J. A. Intercellular skin barrier lipid composition and organization in Netherton syndrome patients. J. Invest. Dermatol. 2014, 134, 1238-1245. 
(38) Crumrine, D.; Khnykin, D.; Krieg, P.; Man, M.-Q.; Celli, A.; Mauro, T. M.; Wakefield, J. S.; Menon, G.; Mauldin, E.; Miner, J. H.; Lin, M.-H.; Brash, A. R.; Sprecher, E.; Radner, F. P. W.; Choate, K.; Roop, D.; Uchida, Y.; Gruber, R.; Schmuth, M.; Elias, P. M. Mutations in Recessive Congenital Ichthyoses Illuminate the Origin and Functions of the Corneocyte Lipid Envelope. J. Investig. Dermatol. 2019, 139, 760-768.

(39) Eckl, K.-M.; Tidhar, R.; Thiele, H.; Oji, V.; Hausser, I.; Brodesser, S.; Preil, M.-L.; Önal-Akan, A.; Stock, F.; Müller, D.; Becker, K.; Casper, R.; Nürnberg, G.; Altmüller, J.; Nürnberg, P.; Traupe, H.; Futerman, A. H.; Hennies, H. C. Impaired Epidermal Ceramide Synthesis Causes Autosomal Recessive Congenital Ichthyosis and Reveals the Importance of Ceramide Acyl Chain Length. J. Investig. Dermatol. 2013, 133, 2202-2211.

(40) Cosmetic Formulation Principles and Practice; Benson, H. A. E.; Walters, K.; Roberts, M. S.; Leite-Silva, V. R., Eds.; CRC Press: Boca Raton,2019.

(41) Farwanah, H.; Raith, K.; Neubert, R. H.; Wohlrab, J. Ceramide profiles of the uninvolved skin in atopic dermatitis and psoriasis are comparable to those of healthy skin. Arch. Dermatol. Res. 2005, 296, 514-521.

(42) Eckl, K. M.; Tidhar, R.; Thiele, H.; Oji, V.; Hausser, I.; Brodesser, S.; Preil, M.; Önal-Akan, A.; Stock, F.; Müller, D.; et al. Impaired Epidermal Ceramide Synthesis Causes Autosomal Recessive Congenital Ichthyosis and Reveals the Importance of Ceramide Acyl Chain Length. J. Invest. Dermatol. 2013, 133, 2202-2211.

(43) Boer, D. E. C.; van Smeden, J.; Al-Khakany, H.; Melnik, E.; van Dijk, R.; Absalah, S.; Vreeken, R. J.; Haenen, C. C. P.; Lavrijsen, A. P. M.; Overkleeft, H. S.; Aerts, J. M. F. G.; Bouwstra, J. A. Skin of atopic dermatitis patients shows disturbed $\beta$-glucocerebrosidase and acid sphingomyelinase activity that relates to changes in stratum corneum lipid composition. Biochim. Biophys. Acta, Mol. Cell Biol. Lipids 2020, 1865, No. 158673.

(44) de Jager, M.; Groenink, W.; Bielsa i Guivernau, R.; Andersson, E.; Angelova, N.; Ponec, M.; Bouwstra, J. A novel in vitro percutaneous penetration model: evaluation of barrier properties with p-aminobenzoic acid and two of its derivatives. Pharm. Res. 2006, 23, 951-960.

(45) Groen, D.; Berthaud, F.; Bouwstra, J. A.; Chapuis, C.; Gooris, G. S.; Boncheva, M. In vitro model systems for studying the impact of organic chemicals on the skin barrier lipids. Biochim. Biophys. Acta, Biomembr. 2014, 1838, 310-318.

(46) Mojumdar, E. H.; Helder, R. W.; Gooris, G. S.; Bouwstra, J. A. Monounsaturated fatty acids reduce the barrier of stratum corneum lipid membranes by enhancing the formation of a hexagonal lateral packing. Langmuir 2014, 30, 6534-6543.

(47) Skolová, B.; Jandovska, K.; Pullmannova, P.; Tesar, O.; Roh, J.; Hrabalek, A.; Vavrova, K. The role of the trans double bond in skin barrier sphingolipids: permeability and infrared spectroscopic study of model ceramide and dihydroceramide membranes. Langmuir 2014, $30,5527-5535$.

(48) Opálka, L.; Kovacik, A.; Maixner, J.; Vavrova, K. Omega-OAcylceramides in skin lipid membranes: effects of concentration, sphingoid base, and model complexity on microstructure and permeability. Langmuir 2016, 32, 12894-12904.

(49) Uche, L. E.; Gooris, G. S.; Beddoes, C. M.; Bouwstra, J. A. New insight into phase behavior and permeability of skin lipid models based on sphingosine and phytosphingosine ceramides. Biochim. Biophys. Acta, Biomembr. 2019, 1861, 1317-1328.

(50) Uche, L. E.; Gooris, G. S.; Bouwstra, J. A.; Beddoes, C. M. High concentration of the ester-linked $\omega$-hydroxy ceramide increases the permeability in skin lipid model membranes. Biochim. Biophys. Acta, Biomembr. 2021, 1863, 183487-183497.

(51) Pullmannová, P.; Ermakova, E.; Kovacik, A.; Opalka, L.; Maixner, J.; Zbytovska, J.; Kucerka, N.; Vavrova, K. Long and very long lamellar phases in model stratum corneum lipid membranes. J. Lipid Res. 2019, 60, 963-971.

(52) Beddoes, C. M.; Rensen, D. E.; Gooris, G. S.; Malfois, M.; Bouwstra, J. A. The Importance of Free Fatty Chain Length on the
Lipid Organization in the Long Periodicity Phase. Int. J. Mol. Sci. 2021, 22, No. 3679.

(53) Školová, B.; Janusova, B.; Zbytovska, J.; Gooris, G.; Bouwstra, J.; Slepicka, P.; Berka, P.; Roh, J.; Palat, K.; Hrabalek, A.; Vavrova, K. Ceramides in the skin lipid membranes: length matters. Langmuir 2013, 29, 15624-15633.

(54) Pullmannová, P.; Pavlíková, L.; Kováčik, A.; Sochorová, M.; Školová, B.; Slepička, P.; Maixner, J.; Zbytovská, J.; Vávrová, K. Permeability and microstructure of model stratum corneum lipid membranes containing ceramides with long (C16) and very long (C24) acyl chains. Biophys. Chem. 2017, 224, 20-31.

(55) Stahlberg, S.; Skolova, B.; Madhu, P. K.; Vogel, A.; Vavrova, K.; Huster, D. Probing the role of the ceramide acyl chain length and sphingosine unsaturation in model skin barrier lipid mixtures by $(2) \mathrm{H}$ solid-state NMR spectroscopy. Langmuir 2015, 31, 4906-4915.

(56) Bouwstra, J. A.; Gooris, G. S.; Dubbelaar, F. E.; Weerheim, A. M.; Ijzerman, A. P.; Ponec, M. Role of ceramide 1 in the molecular organization of the stratum corneum lipids. J. Lipid Res. 1998, 39, 186-196.

(57) Bouwstra, J. A.; Gooris, G. S.; Dubbelaar, F. E.; Ponec, M. Phase behavior of stratum corneum lipid mixtures based on human ceramides: the role of natural and synthetic ceramide $1 . \mathrm{J}$. Invest. Dermatol. 2002, 118, 606-617.

(58) Groen, D.; Gooris, G. S.; Bouwstra, J. A. Model membranes prepared with ceramide EOS, cholesterol, and free fatty acids form a unique lamellar phase. Langmuir 2010, 26, 4168-4175.

(59) Bouwstra, J. A.; Gooris, G. S.; Dubbelaar, F. E.; Ponec, M. Phase behavior of lipid mixtures based on human ceramides: coexistence of crystalline and liquid phases. J. Lipid Res. 2001, 42, $1759-1770$.

(60) McIntosh, T. J.; Stewart, M. E.; Downing, D. T. X-ray diffraction analysis of isolated skin lipids: reconstitution of intercellular lipid domains. Biochemistry 1996, 35, 3649-3653.

(61) Boncheva, M.; Damien, F.; Normand, V. Molecular organization of the lipid matrix in intact stratum corneum using ATR-FTIR spectroscopy. Biochim. Biophys. Acta, Biomembr. 2008, 1778, 1344-1355.

(62) Damien, F.; Boncheva, M. The extent of orthorhombic lipid phases in the stratum corneum determines the barrier efficiency of human skin in vivo. J. Invest. Dermatol. 2010, 130, 611-614.

(63) Wertz, P. W.; Downing, D. T. Physiology, Biochemistry and Molecular Biology of the Skin, 2nd ed.; Oxford University Press: New York, 1991; Vol. 1, pp 205-236.

(64) Gooris, G. S.; Kamran, M.; Kros, A.; Moore, D. J.; Bouwstra, J. A. Interactions of dipalmitoylphosphatidylcholine with ceramidebased mixtures. Biochim. Biophys. Acta, Biomembr. 2018, 1860, 12721281.

(65) Beddoes, C. M.; Gooris, G. S.; Bouwstra, J. A. Preferential arrangement of lipids in the long-periodicity phase of a stratum corneum matrix model. J. Lipid Res. 2018, 59, 2329-2338.

(66) Oguri, M.; Gooris, G. S.; Bito, K.; Bouwstra, J. A. The effect of the chain length distribution of free fatty acids on the mixing properties of stratum corneum model membranes. Biochim. Biophys. Acta, Biomembr. 2014, 1838, 1851-1861.

(67) Wojdyr, M. Fityk: a general-purpose peak fitting program. J. Appl. Crystallogr. 2010, 43, 1126-1128.

(68) Uche, L. E.; Gooris, G. S.; Bouwstra, J. A.; Beddoes, C. M. Barrier Capability of Skin Lipid Models: Effect of Ceramides and Free Fatty Acid Composition. Langmuir 2019, 35, 15376-15388.

(69) Mojumdar, E. H.; Gooris, G. S.; Groen, D.; Barlow, D. J.; Lawrence, M. J.; Deme, B.; Bouwstra, J. A. Stratum corneum lipid matrix: Location of acyl ceramide and cholesterol in the unit cell of the long periodicity phase. Biochim. Biophys. Acta, Biomembr. 2016, $1858,1926-1934$.

(70) Opálka, L.; Kovacik, A.; Pullmannova, P.; Maixner, J.; Vavrova, $\mathrm{K}$. Effects of omega-O-acylceramide structures and concentrations in healthy and diseased skin barrier lipid membrane models. J. Lipid Res. 2020, 61, 219-228. 
(71) de Sousa Neto, D.; Gooris, G.; Bouwstra, J. Effect of the omega-acylceramides on the lipid organization of stratum corneum model membranes evaluated by X-ray diffraction and FTIR studies (Part I). Chem. Phys. Lipids 2011, 164, 184-195.

(72) Groen, D.; Gooris, G. S.; Bouwstra, J. A. New insights into the stratum corneum lipid organization by X-ray diffraction analysis. Biophys. J. 2009, 97, 2242-2249.

(73) Mendelsohn, R.; Moore, D. J. Vibrational spectroscopic studies of lipid domains in biomembranes and model systems. Chem. Phys. Lipids 1998, 96, 141-157.

(74) Mendelsohn, R.; Flach, C. R.; Moore, D. J. Determination of molecular conformation and permeation in skin via IR spectroscopy, microscopy, and imaging. Biochim. Biophys. Acta, Biomembr. 2006, $1758,923-933$.

(75) Janušová, B.; Zbytovska, J.; Lorenc, P.; Vavrysova, H.; Palat, K.; Hrabalek, A.; Vavrova, K. Effect of ceramide acyl chain length on skin permeability and thermotropic phase behavior of model stratum corneum lipid membranes. Biochim. Biophys. Acta, Mol. Cell Biol. Lipids 2011, 1811, 129-137.

(76) Mojumdar, E. H.; Kariman, Z.; van Kerckhove, L.; Gooris, G. S.; Bouwstra, J. A. The role of ceramide chain length distribution on the barrier properties of the skin lipid membranes. Biochim. Biophys. Acta, Biomembr. 2014, 1838, 2473-2483.

(77) Snyder, R. G.; Goh, M. C.; Srivatsavoy, V. J. P.; Strauss, H. L.; Dorset, D. L. Measurement of the growth-kinetics of microdomains in binary $\mathrm{N}$-alkane solid-solutions by infrared-spectroscopy. J. Phys. Chem. A 1992, 96, 10008-10019.

(78) Snyder, R. G. Vibrational Correlation Splitting and Chain Packing for the Crystalline N-Alkanes. J. Chem. Phys. 1979, 71, 32293235.

(79) Berkers, T.; van Dijk, L.; Absalah, S.; van Smeden, J.; Bouwstra, J. A. Topically applied fatty acids are elongated before incorporation in the stratum corneum lipid matrix in compromised skin. Exp. Dermatol. 2017, 26, 36-43.

(80) Mendelsohn, R.; Liang, G. L.; Strauss, H. L.; Snyder, R. G. IR spectroscopic determination of gel state miscibility in long-chain phosphatidylcholine mixtures. Biophys. J. 1995, 69, 1987-1998.

(81) Gooris, G. S.; Bouwstra, J. A. Infrared spectroscopic study of stratum corneum model membranes prepared from human ceramides, cholesterol, and fatty acids. Biophys. J. 2007, 92, 2785-2795.

(82) Bouwstra, J. A.; Dubbelaar, F. E.; Gooris, G. S.; Ponec, M. The lipid organisation in the skin barrier. Acta Derm.-Venereol. 2000, 208, 23-30.

(83) Ramos, A. P.; Lafleur, M. Chain Length of Free Fatty Acids Influences the Phase Behavior of Stratum Corneum Model Membranes. Langmuir 2015, 31, 11621-11629.

(84) Mojumdar, E. H.; Gooris, G. S.; Barlow, D. J.; Lawrence, M. J.; Deme, B.; Bouwstra, J. A. Skin lipids: localization of ceramide and fatty acid in the unit cell of the long periodicity phase. Biophys. J. 2015, 108, 2670-2679.

(85) Beddoes, C. M.; Gooris, G. S.; Foglia, F.; Ahmadi, D.; Barlow, D. J.; Lawrence, M. J.; Demé, B.; Bouwstra, J. A. Arrangement of Ceramides in the Skin: Sphingosine Chains Localize at a Single Position in Stratum Corneum Lipid Matrix Models. Langmuir 2020, 36, 10270-10278.

(86) Mojumdar, E. H.; Groen, D.; Gooris, G. S.; Barlow, D. J.; Lawrence, M. J.; Deme, B.; Bouwstra, J. A. Localization of cholesterol and fatty acid in a model lipid membrane: a neutron diffraction approach. Biophys. J. 2013, 105, 911-918. 